OAK RIDGE NATIONAL LABORATORY
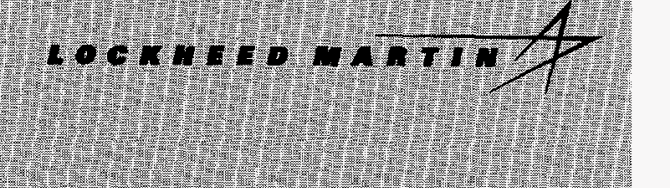

II)
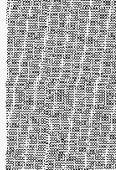

Evaluation of Improved Techniques for the Removal of Fission Products from Process Wastewater and Groundwater:

FY 1996 Status

D. A. Bostick

B. B. Guo

RECEIVED AUG 081997 OS.TI

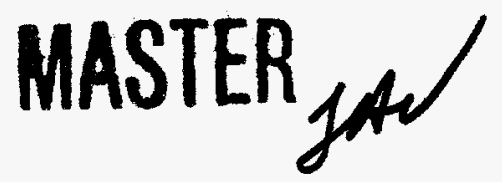

DISTFUPUINON OF THIS DOCUMENT IS UMMMTES 
This report has been reproduced directly from the best available copy.

Available to DOE and DOE contractors from the Office of Scientific and Technical Intormation, P.O. Box 62, Oak Ridge, TN 37831; prices available from (615) 576-8401, FTS 626-8401.

Available to the public from the National Technical Information Service, U.S. Department of Commerce, 5285 Port Royal Rd., Springfield, VA 22161.

This report was prepared as an account of work sponsored by an adency of the United States Government. Neither the United States Government nor any agency thereof, nor any of their employees, makes any warranty, express or implied, or assumes any legal liability or responsibility for the accuracy, com pleteness, or usefuiness of any information, apparatus, product, or process disclosed, or represents that its use would not infringe privately owned rights. Reference herein to any specific commercial product, process, or service by trade name, trademark, manufacturer, or otherwise. does not necessarily constitute or imply its endorsement, recommendation, or favoring by the United States Government or any agency thereof. The views and opinions of authors expressed herein do not necessarily state or refiect those of the United States Government or any agency thereof. 


\section{DISCLAIMER}

Portions of this document may be illegible electronic image products. Images are produced from the best available original document. 
Chemical Technology Division

\title{
EVALUATION OF IMPROVED TECHNIQUES FOR THE REMOVAL OF FISSION PRODUCTS FROM PROCESS WASTEWATER AND GROUNDWATER: FY 1996 STATUS
}

D. T. Bostick and B. Guo*

\footnotetext{
"Oak Ridge Research Institute, Oak Ridge, Tennessee.
}

Date Prepared-September 1996

Date Published - July 1997

\section{Prepared for the}

U.S. Department of Energy Office of Science and Technology Efficient Separations and Processing Crosscutting Program

\author{
Prepared by the \\ OAK RIDGE NATIONAL LABORATORY \\ Oak Ridge, Tennessee 37831-6285 \\ managed by \\ LOCKHEED MARTIN ENERGY RESEARCH CORP. \\ for the \\ U.S. DEPARTMENT OF ENERGY \\ under contract DE-AC05-96OR22464
}





\section{CONTENTS}

LIST OF TABLES $\ldots \ldots \ldots \ldots \ldots \ldots \ldots \ldots \ldots \ldots \ldots \ldots \ldots \ldots \ldots \ldots \ldots \ldots$

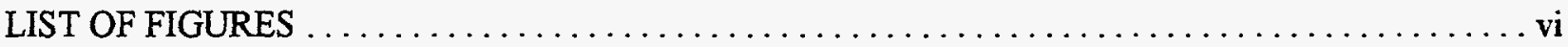

ACRONYMS AND ABBREVIATIONS $\ldots \ldots \ldots \ldots \ldots \ldots \ldots \ldots \ldots \ldots \ldots \ldots \ldots \ldots \ldots \ldots$ vii

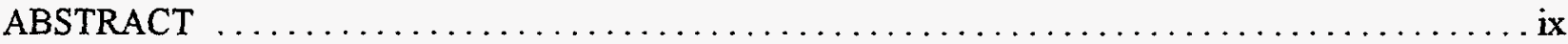

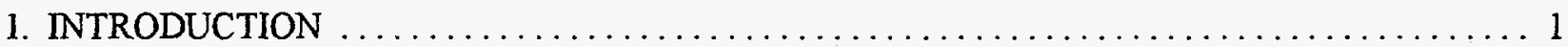

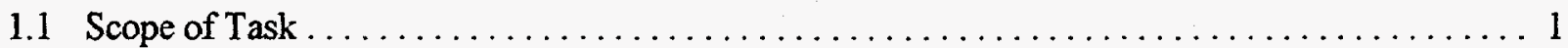

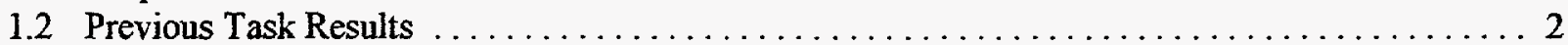

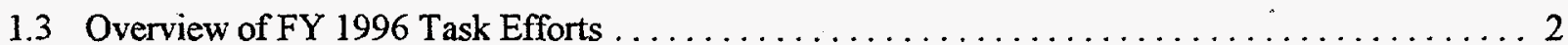

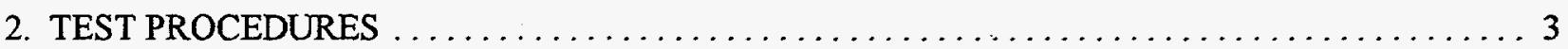

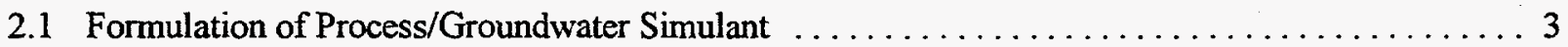

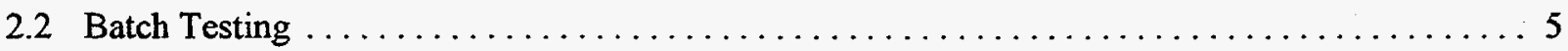

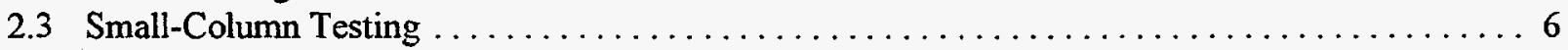

3. PHYSICAL AND CHEMICAL CHARACTERIZATION OF THE SORBENTS $\ldots \ldots \ldots \ldots \ldots .7$

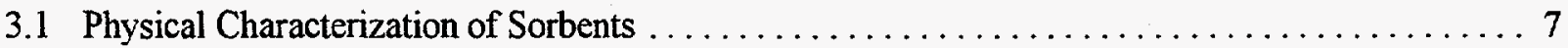

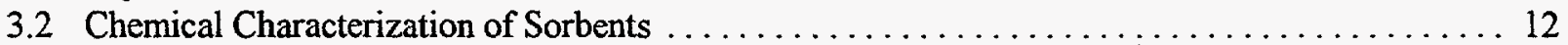

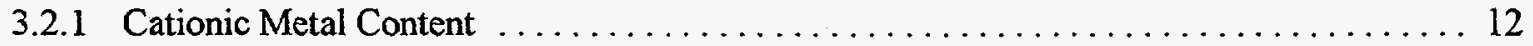

3.2 .2 Ion-Exchange Capacity and Ion-Exchange Ratio $\ldots \ldots \ldots \ldots \ldots \ldots \ldots \ldots \ldots$

3.2.3 Estimation of Particle and Film Diffusion Coefficients $\ldots \ldots \ldots \ldots \ldots \ldots \ldots \ldots \ldots 22$

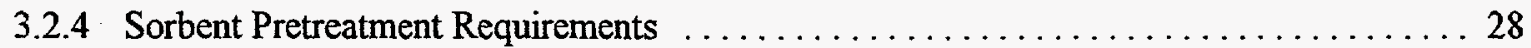

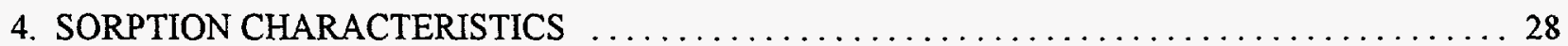

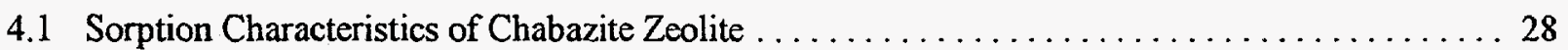

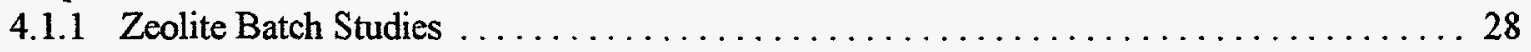

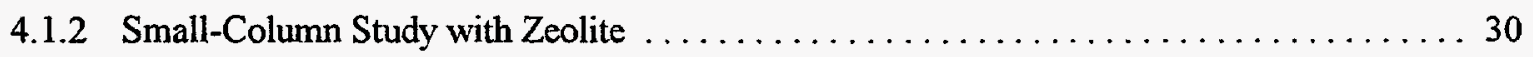

4.2 Sorption Characteristics of R-F Ion-Exchange Resin $\ldots \ldots \ldots \ldots \ldots \ldots \ldots \ldots \ldots \ldots \ldots \ldots \ldots$

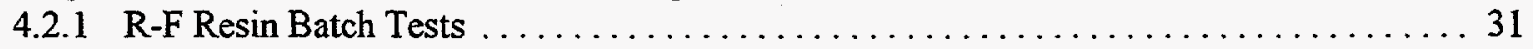

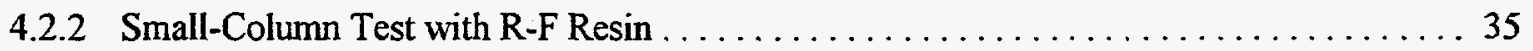

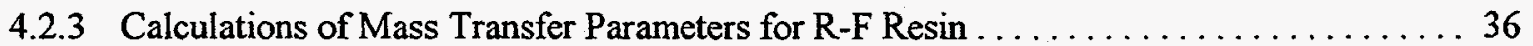

4.3 Sorption Characteristics of Sodium Nonatitanate $\ldots \ldots \ldots \ldots \ldots \ldots \ldots \ldots \ldots \ldots \ldots \ldots \ldots$

4.4 Sorption Characteristics of Potassium Iron(II) Hexacyanoferrate $\ldots \ldots \ldots \ldots \ldots \ldots \ldots \ldots$

5. SCALEUP ISSUES PERTINENT TO THE IMPLEMENTATION OF TASK SORBENTS $\ldots \ldots \ldots 48$

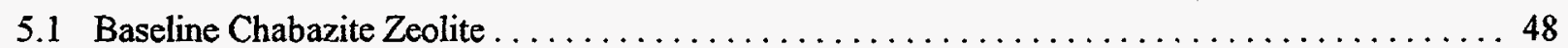

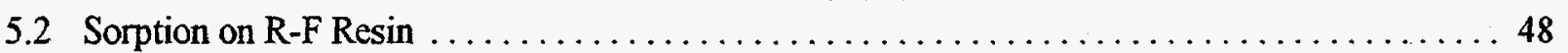

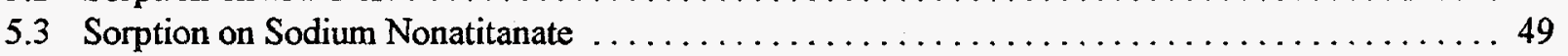

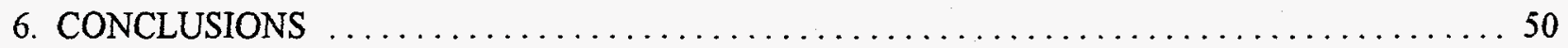

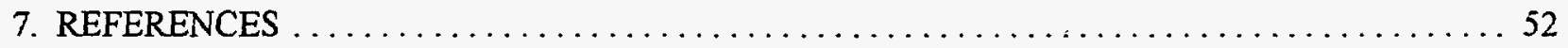





\section{LIST OF TABLES}

Table

1 Cationic composition of wastewater simulants for batch testing $\ldots \ldots \ldots \ldots \ldots \ldots \ldots \ldots \ldots$

2 Physical characterization of as-received sorbents $\ldots \ldots \ldots \ldots \ldots \ldots \ldots \ldots \ldots \ldots$

3 Volume distribution of nonatitanate powder in water $(\operatorname{lot} 8212-94-3) \ldots \ldots \ldots \ldots \ldots \ldots \ldots$

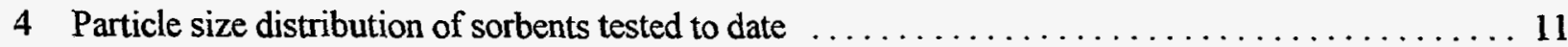

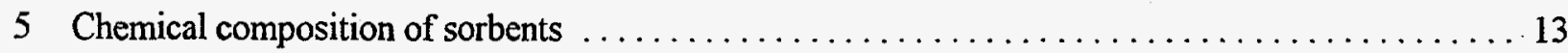

6 Strontium ion exchange on sodium-modified chabazite zeolite $(0.5 \mathrm{~g}) \ldots \ldots \ldots \ldots \ldots \ldots$

7 Strontium ion exchange on water-washed $\mathrm{R}-\mathrm{F}$ resin $(0.5 \mathrm{~g}) \ldots \ldots \ldots \ldots \ldots \ldots \ldots \ldots \ldots \ldots$

8 Strontium ion exchange on as-received nonatitanate powder $(0.5 \mathrm{~g}) \ldots \ldots \ldots \ldots \ldots \ldots \ldots$

9 Strontium ion exchange on as-received nonatitanate pellet $(0.5 \mathrm{~g}) \ldots \ldots \ldots \ldots \ldots \ldots \ldots$

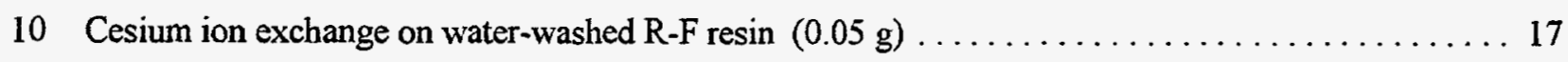

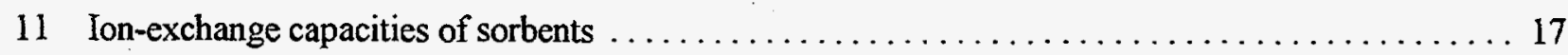

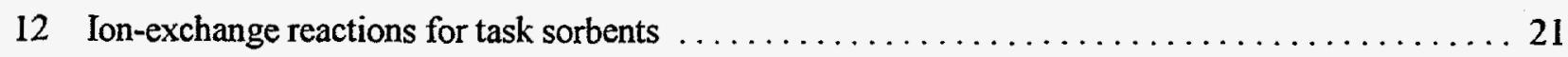

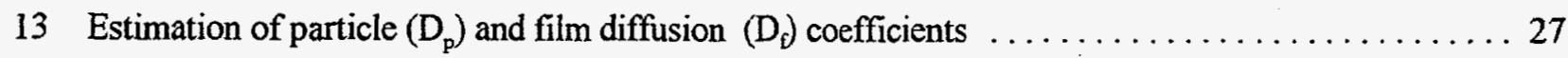

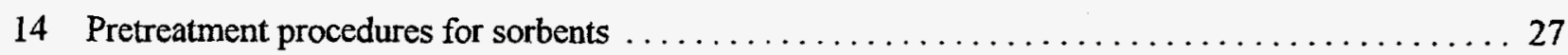

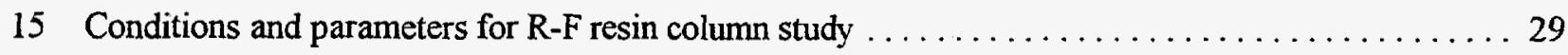

16 Conditions and parameters for zeolite column study $\ldots \ldots \ldots \ldots \ldots \ldots \ldots \ldots \ldots \ldots \ldots$

17 Effect of increased alkaline earth metal content on rate of cation sorption $\ldots \ldots \ldots \ldots \ldots \ldots . \ldots 42$ 


\section{LIST OF FIGURES}

Figure

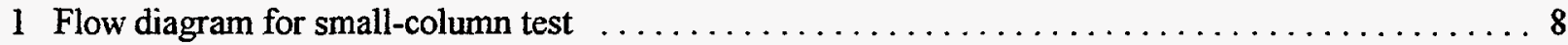

2 Determination of cesium ion-exchange ratio on water-washed $\mathrm{R}-\mathrm{F}$ resin $\ldots \ldots \ldots \ldots \ldots \ldots \ldots$

3 Strontium equilibration time on $20 \mathrm{mg}$ of sorbent $\ldots \ldots \ldots \ldots \ldots \ldots \ldots \ldots \ldots \ldots \ldots \ldots$

4 Calculation of strontium particle diffusion coefficient $\ldots \ldots \ldots \ldots \ldots \ldots \ldots \ldots \ldots \ldots \ldots \ldots \ldots \ldots$

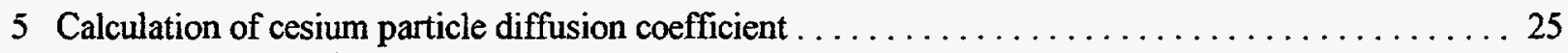

6 Strontium sorption on pretreated $\mathrm{R}-\mathrm{F}$ resin $\ldots \ldots \ldots \ldots \ldots \ldots \ldots \ldots \ldots \ldots \ldots \ldots \ldots \ldots \ldots \ldots \ldots \ldots \ldots$

7 Metal(II) sorption data on water-washed $\mathrm{R}-\mathrm{F}$ resin $\ldots \ldots \ldots \ldots \ldots \ldots \ldots \ldots \ldots \ldots \ldots \ldots \ldots \ldots \ldots$

8 Breakthrough curves of strontium and cesium on water-washed $\mathrm{R}-\mathrm{F}$ resin $\ldots \ldots \ldots \ldots \ldots \ldots$

9 Strontium sorption on sodium nonatitanate powder $\ldots \ldots \ldots \ldots \ldots \ldots \ldots \ldots \ldots \ldots \ldots$

10 Change in cation sorption ratios as a function of sorbent contact time $\ldots \ldots \ldots \ldots \ldots \ldots \ldots$

11 Effect of initial metal content on the rate of strontium uptake on nonatitanate powder ....... 45 


\title{
ACRONYMS AND ABBREVIATIONS
}

\author{
AA atomic absorption \\ BET Brunauer, Emmett, Teller \\ BSC Boulder Scientific Company \\ BV bed volume \\ $\mathrm{C}_{\mathrm{s}}$ saturation concentration in solution \\ CST crystalline silicotitanate \\ $D_{\mathrm{f}} \quad$ film diffusion coefficient \\ $\mathrm{D}_{\mathrm{p}} \quad$ particle diffusion coefficient \\ DF decontamination factor \\ ESP Efficient Separations and Processing Crosscutting Program \\ FY fiscal year \\ ICP inductively coupled plasma \\ $K_{d} \quad$ distribution coefficient \\ LLW low-level waste \\ MOH MOH hardness scale \\ ORNL Oak Ridge National Laboratory \\ PWTP Process Waste Treatment Plant \\ $\mathrm{Q}_{e} \quad$ amount of nuclide sorbed per unit mass of sorbent \\ rcf relative centrifugal force \\ $R_{s} \quad$ sorption ratio \\ R-F resorcinol-formaldehyde \\ SRL Savannah River Laboratory \\ TRU transuranic \\ USDOE U.S. Department of Energy \\ WAG Waste Area Grouping
}




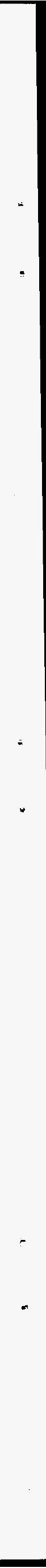


This report describes laboratory results acquired in the course of evaluating new sorbents for the treatment of radiologically contaminated groundwater and process wastewater. During FY 1996, the evaluation of resorcinol-formaldehyde (R-F) resin for the removal of cesium and strontium from wastewaters was completed. Additionally, strontium sorption on sodium nonatitanate powder was characterized in a series of multicomponent batch studies. Both of these materials were evaluated in reference to a baseline sorbent, natural chabazite zeolite.

A considerable amount of literature is available that discusses the applications of R-F resin and nonatitanate in the remediation of high-alkaline, high-salt wastes. As one might expect, there is a significant difference in the cationic content between highly alkaline tank wastes and near-neutral wastewaters. In particular, the soluble calcium and magnesium ion concentrations in near-neutral solutions are higher than those of tank wastes. Conversely, the sodium-ion contents in tank wastes are several orders of magnitude higher than those in wastewater. The dissimilarity in the ionic contents of the two waste streams implies that much of the literature relating to the decontamination efficiency of a given sorbent in tank waste is not directly applicable to the current study. Experimental results obtained in FY 1996, under Task OR16C312 Subtask A of the Efficient Separations and Processing Crosscutting Program, help to delineate and interpret differences in the application of R-F resin and nonatitanate sorbents for wastewater applications.

The pretreatment of both R-F resin and nonatitanate is advised for low-ionic-strength wastewater processing. These sorbents contain greater than $0.4 \mathrm{meq} / \mathrm{g}$ of excess potassium and sodium, respectively, in the as-received material. The ion-exchange capacity has been determined for each sorbent. Relative capacities, based on strontium uptake on the sorbents, are $2.2,3.2$, and $3.1 \mathrm{meq} / \mathrm{g}$ for sodium-modified zeolite, water-washed R-F resin, and as-received nonatitanate powder, respectively. The cesium capacity for $\mathrm{R}-\mathrm{F}$ resin is $1.7 \mathrm{meq} / \mathrm{g}$; cesium does not sorb appreciably on nonatitanate. The ratio of milliequivalents of sorbent counterion released per milliequivalent of strontium sorbed varies among the sorbents tested. The ion-exchange ratio is near unity between sodium and strontium on chabazite and between potassium and cesium on R-F resin. However, the noninteger ratios for strontium sorption on the resin and on nonatitanate indicate that physical sorption, in addition to ion exchange, may contribute to strontium uptake. Estimates of the strontium and cesium molal equilibrium coefficients were also derived from the exchange capacity data. For strontium exchange on all sorbents, the molal equilibrium coefficients are all greater than one, indicating 
that the exchangers preferentially sorb strontium over the counterion. This is not the case for cesium sorption on the R-F resin, suggesting that the resin is more selective for the potassium counterion over cesium.

In addition to strontium, both calcium and magnesium sorb on R-F resin and nonatitanate. Because the sorption ratio of each alkaline earth metal is approximately equivalent on the resin, strontium sorption must be estimated as a function of total alkaline earth metal content in the wastewater. The sorption ratios of alkaline earth metals on nonatitanate are both concentration and time dependent. The strontium and calcium sorption ratios increase with time to a peak value, whereas the magnesium sorption ratio remains constant with time. Beyond the peak sorption time, strontium desorbs from the nonatitanate. Relative sorption ratios for strontium in process wastewater are $17,000,1200$, and $2000 \mathrm{~L} / \mathrm{kg}$ on zeolite, $\mathrm{R}-\mathrm{F}$ resin, and nonatitanate, respectively. (The value stated for the nonatitanate reflects the maximum value for strontium observed at the peak sorption time.) As the result of a calcium concentration that is approximately 2.5 times greater than that of process water, the strontium sorption ratios decrease to $10,000,600$, and 1000 in groundwater on the respective sorbents.

A small-column test was performed to validate the batch-testing results of $R-F$ resin. Calcium, magnesium, and strontium cations elute simultaneously from the resin column whereas separate breakthrough fronts are observed for each alkaline earth metal on a similarly sized zeolite column. The concurrent breakthrough of alkaline earth metals again suggests that the resin has no preference for strontium over calcium and magnesium. The relative points of $50 \%$ breakthrough for strontium are 525 bed volumes (BV) on the resin, as compared with $15,000 \mathrm{BV}$ on zeolite. Comparable breakthrough values for cesium are 6,400 on the resin and 50,000 BV on zeolite. A small-column test has not yet been run to observe breakthrough characteristics on nonatitanate.

Considering that the estimated strontium sorption ratios for the R-F resin and nonatitanate powder are an order of magnitude lower than that for the baseline zeolite, it seems more prudent at this time to perform scoping studies on an alternative sorbent and postpone further data acquisition for the resin and nonatitanate.

Efforts in FY 1997 will focus on the evaluation of engineered crytalline silicotitanate for wastewater treatment applications. 


\section{INTRODUCTION}

\subsection{SCOPE OF TASK}

One of the goals of this task is to identify the technical issues that govern the selection of ion-exchange materials in the treatment of radiologically contaminated process wastewater and groundwater. Once these issues are understood, new sorbent materials, ion-exchange materials, or other processes will be evaluated in the light of these drivers. Ultimately, laboratory results will be summarized for the end user so that an appropriate wastewater treatment can be selected for a given site.

New sorbents to be evaluated in this task will be those that have demonstrated an enhanced selectivity for the removal of radioactive ${ }^{90} \mathrm{Sr},{ }^{134,137} \mathrm{Cs},{ }^{3} \mathrm{H}$, and ${ }^{99} \mathrm{Tc}$, as compared with standard treatment methods currently in use. Because the principal radioactive contaminants in U.S. Department of Energy (USDOE) wastewaters are ${ }^{90} \mathrm{Sr}$ and ${ }^{134,137} \mathrm{Cs}$, the initial focus of this task has been to evaluate sorbents that have the greatest potiential for removing these two nuclides from contaminated process water and groundwater. To date, resorcinol-formaldehyde (R-F) resin, developed at Savannah River Laboratory (SRL), and sodium nonatitanate, developed by Texas A\&M and AlliedSignal Research, have been evaluated. Future efforts will include the evaluation of crystalline silicotitanates, developed at Sandia National Laboratory and Texas A\&M, and molecular recognition materials, developed by IBC Advanced Technologies, Inc., and immobilized using $3 \mathrm{M}$ Corporation technology.

Batch shaker tests are used to compare the performance characteristics of the newly developed media with those obtained with standard, commercially available material. These equilibrium tests are performed under various treatment conditions ( $\mathrm{pH}$, temperature, waste composition) for the most promising materials. Additional sorption studies are performed with actual wastewater in batch experiments to verify data acquired using a standard wastewater simulant. Once batch testing of a treatment method has been completed, dynamic column tests are performed, using the most successful sorbents, to obtain the column operating parameters required for scaling up the technology.

This report summarizes sorption data acquired in FY 1996 using R-F resin and sodium nonatitanate powder and pellets. A brief description of the characteristics of the baseline treatment method is included to permit a comparison with FY 1996 data obtained for newly emerging processes. In addition, a short description of FY 1995 results is also incorporated so that laboratory directions taken in FY 1996 can be understood in light of these earlier data. 


\subsection{PREVIOUS TASK RESULTS}

The major effort during FY 1994 and a portion of FY 1995 was the characterization of the baseline treatment technology-i.e., nuclide sorption on natural chabazite zeolite. Cesium and strontium sorption on zeolite was determined for batchwise treatment of both a wastewater simulant and the corresponding actual wastewater. From batch testing, radionuclide sorption on the zeolite was fit to an empirical Freundich sorption model so that ${ }^{90} \mathrm{Sr}$ and ${ }^{137} \mathrm{Cs}$ sorption on zeolite columns could be predicted. Zeolite sorption efficiency was determined in the presence of the major cations present in wastewater (e.g., $\mathrm{Na}, \mathrm{Ca}, \mathrm{K}$, and $\mathrm{Mg}$ ) to determine the impact that variations in water composition might have. A test with a small zeolite column was completed in FY 1995 to observe ${ }^{90} \mathrm{Sr}$ and ${ }^{137} \mathrm{Cs}$ breakthrough characteristics under dynamic flow conditions. The performance of the chabazite zeolite for the treatment of process/groundwater samples has been summarized in ORNL topical reports. ${ }^{1,2}$ The combination of sorption data and column performance served to define zeolite characteristics, as well as to establish standardized testing procedures for the direct comparison of this baseline treatment with newer sorbent technology as it develops.

\subsection{OVERVIEW OF FY 1996 TASK EFFORTS}

In lieu of an available new inorganic exchanger, R-F resin was selected in FY 1995 as the first in a series of new sorbents that were tested under this task. A portion of FY 1996 was used to complete this effort. Studies during FY 1995 used radioanalytical data to determine the fate of cesium and strontium in solutions treated with the resin. Supporting inductively coupled plasma (ICP) spectrophotometric data were acquired during FY 1996 to help interpret the nonlinear isotherms observed in FY 1995 strontium sorption tests. Strontium and cesium sorption characteristics on the resin were also observed in a small-column test performed in FY 1996.

The first new inorganic sorbent for the removal of strontium became available for evaluation in FY 1996. Two samples of sodium nonatitanate, $\mathrm{Na}_{4} \mathrm{Ti}_{9} \mathrm{O}_{20} \cdot x \mathrm{H}_{2} \mathrm{O}$, were received (from AlliedSignal Research and Technology) in the form of a fine powder and as cylindrical pellets, respectiviely. Pretreatment options for the nonatitanate powder were explored; in addition, the cation content and ion-exchange capacity of this material were measured. Equilibrium studies were completed to determine the optimum contact time for nonatitanate powder in $10 \mathrm{~mL}$ of simulant. Final testing in FY 1996 focused on observing the competition of other cations for strontium sorption sites on the nonatitanate.

Also, in FY 1996, a sample of a Russian commercial treatment reagent was received. This material, referred to as FEZHEL (or ANFEZH), is available through the JSC "Compomet Cantec" of Yekaterinburg, Russia. It consists of wood cellulose fibers coated with potassium iron hexacyanoferrate. At the request of 
ESP management, a limited evaluation of this sorbent was performed to determine whether it might have applications for wastewater treatment in the United States. In a short scoping study, the as-received material was sized, the equilibration mixing time was determined, and a single batch isotherm profile was developed. If ESP program management feels that these preliminary results are sufficiently promising, further batch testing of this particular sorbent will be resumed.

\section{TEST PROCEDURES}

\subsection{FORMULATION OF PROCESS/GROUNDWATER SIMULANT}

Accurate comparative testing of new sorbent materials requires that experimentation be performed under defined, consistent conditions. To accomplish this need, each of the sorbent materials was tested by treating a synthetic wastewater of standard composition according to a specific experimental protocol detailed in the paragraphs below. The formulation of the simulant, as presented in Table 1 , is based on reviews ${ }^{1,2}$ of the compositions of local USDOE wastewater and groundwater. The chemical makeup of the Process Waste Treatment Plant (PWTP) feed was found to be representative of waste streams in local USDOE sites and also falls within the ranges of concentration for the general description for groundwater composition. ${ }^{3}$ The chemical composition of the simulant, therefore, is derived from the composition of this particular feed stream. Grab samples of this wastewater provide the source of actual process water for sorbent tests.

In FY 1995 the scope of the evaluation program was broadened to encompass the treatment of contaminated groundwater that is specific to the Oak Ridge National Laboratory (ORNL) site. Toward this end, a second simulant representing local groundwater was prepared by augmenting the calcium concentration in the wastewater simulant to $100 \mathrm{ppm}$ with the addition of calcium chloride. This upper concentration of calcium represents a typical value observed from a groundwater quality monitoring well located at the downgradient perimeter to the Waste Area Grouping (WAG) 5 on the ORNL reservation. Grab samples taken from this location are used to test sorbents in actual groundwater treatment applications.

Strontium was included in each simulant at a level of $0.1 \mathrm{mg} / \mathrm{L}$ to reflect the average concentration of total strontium in the PWTP feed stream. This strontium concentration is also typical of process water in the local USDOE area and represents a midrange value for groundwater. Both ${ }^{134} \mathrm{Cs}$ and ${ }^{137} \mathrm{Cs}$ are normally absent in local on-site groundwater but are present at an average level of $300 \mathrm{~Bq} / \mathrm{L}$ in PWTP influent. The total ${ }^{137} \mathrm{Cs}$ added to the simulant was present at a tracer level of $1.12 \times 10^{6} \mathrm{~Bq} / \mathrm{L}$ and reflects the upper limit for cesium activity typical of process wastewater. 
Table 1. Cationic composition of wastewater simulants for batch testing

\begin{tabular}{lcc}
\hline & \multicolumn{2}{c}{$\begin{array}{c}\text { Concentration } \\
\text { (mg/L) }\end{array}$} \\
\cline { 2 - 3 } $\begin{array}{l}\text { Cation } \\
\text { component }\end{array}$ & $\begin{array}{c}\text { Process } \\
\text { wastewater }\end{array}$ & Groundwater \\
\hline $\mathrm{Ca}$ & 39 & 100 \\
$\mathrm{Cs}$ & 0.00034 & 0.00034 \\
$\mathrm{Fe}$ & 0.4 & 0.4 \\
$\mathrm{~K}$ & 1 & 1 \\
$\mathrm{Mg}$ & 8 & 8 \\
$\mathrm{Na}$ & 15 & 15 \\
$\mathrm{Sr}$ & 0.1 & 0.1 \\
\hline
\end{tabular}




\subsection{BATCH TESTING}

Sorption measurements were made in long-term batch equilibrium tests. In these tests, the solutions and exchangers were contacted in screw-cap polycarbonate centrifuge tubes by mixing on a Labquake ${ }^{\mathrm{TM}}$ shaker, which rocked the samples from $-45^{\circ}$ to $+45^{\circ}$ from horizontal at 20 cycles per minute. Three samples were included in each data set. Solution volumes were determined from the weight and density of the wastewater simulant or the actual wastewater sample. The sorbent was weighed directly and added to the tubes, which were weighed at the beginning and the end of the equilibration periods to determine any solution loss. At the conclusion of the equilibration period, the tubes were centrifuged for $30 \mathrm{~min}$ at 5000 relative centrifugal force (rcf). The solutions generated from zeolite or R-F resin studies were clarified again by filtering the centrifuged supernate by using a plastic syringe fitted with a $0.45-\mu \mathrm{m}$-pore nylon membrane filter. Because of the finer particle size of the sorbent, the solutions generated in the nonatitanate studies were filtered with a $0.1-\mu \mathrm{m}$-pore polyethersulfone membrane filter.

The ${ }^{85} \mathrm{Sr}$ and ${ }^{137} \mathrm{Cs}$ count rates were determined with a Canberra Series 90 gamma spectrometer. Twomilliliter samples were counted for $1000 \mathrm{~s}$ in a germanium well detector. Data for ${ }^{85} \mathrm{Sr}$ were corrected for the interference of ${ }^{137} \mathrm{Cs}$ at the $514-\mathrm{keV}$ peak by using a linear regression line developed with ${ }^{137} \mathrm{Cs}$ standards.

Test data were used in the following calculations:

Decontamination factor (DF) $=\mathrm{C}_{\mathrm{i}} / \mathrm{C}_{\mathrm{f}}$,

Sorption ratio $\left(\mathrm{R}_{\mathrm{s}}, \mathrm{L} / \mathrm{kg}\right)=\left(\mathrm{C}_{\mathrm{i}}-\mathrm{C}_{\mathrm{f}}\right) \mathrm{V} / \mathrm{C}_{\mathrm{f}} \mathrm{W}$,

Concentrations in solution $\left(M_{f}\right.$, meq $\left./ L\right)=M_{i} \times C_{i} / C_{f}$,

Concentrations on the exchangers $\left(M_{e}, \operatorname{meq} / \mathrm{kg}\right)=M_{f} \times R_{s}$, where

$\mathrm{C}_{\mathrm{i}}=$ count rate of the initial solution;

$\mathrm{C}_{\mathrm{f}}=$ count rate of the final solution;

$\mathrm{V}=$ initial volume of the solution, $\mathrm{mL}$;

$\mathrm{W}=$ exchanger weight, $\mathrm{g}$;

$M_{i}=$ concentration in initial solution, meq $/ \mathrm{L}$;

$M_{f}=$ concentration in final solution, $\mathrm{meq} / \mathrm{L}$.

The sorption ratio $\left(R_{s}\right)$ is equivalent to the distribution coefficient $\left(K_{d}\right)$ if equilibrium conditions are assumed. The exchanger weight is reported on a dry-weight basis by correcting for moisture content of the sorbent. In this way, a direct comparison of sorption efficiency can be made among sorbent materials. 
The fate of competing cations in nonradioactive solutions was determined using a Thermo Jarrell-Ash IRIS/CID ICP spectrophotometer in companion, untraced experiments. A Perkin-Elmer 5000 atomic absorption (AA) spectrophotometer was used to characterize the cation contents of radioactive solutions.

\subsection{SMALL-COLUMN TESTING}

Small-column testing more accurately reflects the sorption characteristics of sorbent material under dynamic flow conditions. The dimensions of a sorbent column are selected primarily on the basis of the diameter of the average sorbent particle, although results of previous small-column experiments are used to modify initial estimates to allow for practical limitations in preparing large volumes of simulant and in limiting the duration of the column test. Although the optimum column diameter should be at least 40 times greater than the average particle diameter (typically $0.059 \mathrm{~cm}$, or $30 \mathrm{mesh}$ ), a factor of 20 is adequate for testing. A $1-\mathrm{cm}$ column diameter meets the above needs and is used for comparative testing of the sorbents. The optimum length of the column should be greater than, or equal to, 4 times the column diameter; the typical column aspect ratio for testing is between 4 and 5 . Approximately $2 \mathrm{~g}$ of preconditioned sorbent was packed in the 1-cm-diam columns, resulting in a bed volume of $4-5 \mathrm{~mL}$.

A 1-cm column was prepared by slowly adding prepared sorbent from a weighed container to a 1-cm column containing a known volume of water. The sorbent was added to the column to a bed depth of $4.5 \mathrm{~cm}$, and then the dry sorbent container was reweighed to determine the weight of sorbent added to the column. Excess water above the column bed was collected and weighed. The difference between the initial water volume in the column and the volume of water displaced by sorbent represented the pore volume of the sorbent column. The pore fraction was equivalent to the measured pore volume of the $1-\mathrm{cm}$ column divided by the column volume calculated on the basis of a $4.5-\mathrm{cm}$ bed height.

Large volumes of wastewater simulant were prepared by adding dry chemicals to $100 \mathrm{~L}$ of nanopure water and adjusting the $\mathrm{pH}$ of the column feed by sparging $\mathrm{CO}_{2}$ gas into the solution for about an hour. The $\mathrm{pH}$ of the solution decreased to 5 , which enhanced the solubility of the added chemicals; however, it stabilized at a value of 7 after being equilibrated for a few days to match that of the simulant used in batch testing. The solution was filtered with a $0.45-\mu \mathrm{m}$ Supor ${ }^{\mathrm{TM}}$ filter membrane, recommended by the vendor for the clarification of groundwater samples. Stable strontium and cesium were added to the simulant at this point. A sample of the final simulant solution was analyzed for ICP metals and nuclide content. The ${ }^{85} \mathrm{Sr}$ and

${ }^{137} \mathrm{Cs}$ tracers were added to $20-\mathrm{L}$ aliquots of the feed solution; 2-mL samples from each aliquot were retained to determine the initial activity of the feed solution. 
A Rainin Rabbit peristaltic pump was used to transfer the traced simulant through a second $0.45-\mu \mathrm{m}$ Supor ${ }^{\mathrm{TM}}$ filter membrane into the base of the sorbent column (Fig. 1). The flow rate of simulant feed was set at $1.25 \mathrm{~mL} / \mathrm{min}$ to maintain a linear flow velocity similar to that of successful earlier column tests. An automatic fraction collector was used to collect the column effluent over a 6 -h period (or $460 \mathrm{~mL}$ per fraction.) The actual fraction volume was determined by multiplying the value for the density of the simulant $(0.9965 \mathrm{~g} / \mathrm{mL})$ by the tared weight of the solution in the fraction. Aliquots of early column fractions were acidified and submitted for ICP analysis. The nuclide content of each fraction was determined.

\section{PHYSICAL AND CHEMICAL CHARACTERIZATION OF THE SORBENTS}

\subsection{PHYSICAL CHARACTERIZATION OF SORBENTS}

A number of physical parameters are important in assessing the performance of a given sorbent. Some of these characteristics include the sorbent density, surface moisture content, surface area, pore size, pore volume, particle size, degree of particle swelling, and mechanical stability. Table 2 summarizes the available physical data for each of the as-received sorbents. Much of this information is available for the baseline zeolite sorbent, primarily through the manufacturer's product literature. Limited unpublished data for the R-F resin ${ }^{4}$ and nonatitanate powder and pellets ${ }^{5}$ include the dry-weight density values of $0.7,0.9$, and $1.4 \mathrm{~g} / \mathrm{cm}^{3}$, respectively. As can be seen in Table 2 , considerable data must still be determined and made available to end users before scaleup calculations can be made. Thus far, experimental data have been obtained in-house to quantitate the surface moisture of the sorbents studied. Results suggest that the asreceived resin has a significantly higher surface moisture content than that of any of the inorganic sorbents. Additionally, the surface moisture content of the nonatitanate powder suggests that $4 \mathrm{~mol}$ of water are associated with 1 mol of nonatitanate.

Pore characteristics of the R-F resin have not been reported in the literature; only limited data are available for the nonatitanate sorbents. An estimate of pore size for the resin can be made, based on the volume needed by a potassium ion to fill the meta position of resorcinol. The diameter of a dehydrated potassium ion is $2.66 \AA$. The pore size of the nonatitanate can be extrapolated, given the fact that the $d$-spacings, or the interlayer distances of the nonatitanate crystalline structure, are 6.9 and $10 \AA$ in the anhydrous and fully hydrated forms, respectively. ${ }^{6}$ A more accurate determination of pore size, degree of porosity, and pore size distribution for both the resin and the nonatitanate sorbents still needs to be made. Published properties for the nonatitanate pellet include a Brunauer, Emmett, Teller (BET) surface area of $52.5 \mathrm{~m}^{2} / \mathrm{g}$, a total pore volume of $0.108 \mathrm{~mL} / \mathrm{g}$, and a radial crush strength of 518 psi. $^{\text {? }}$ 


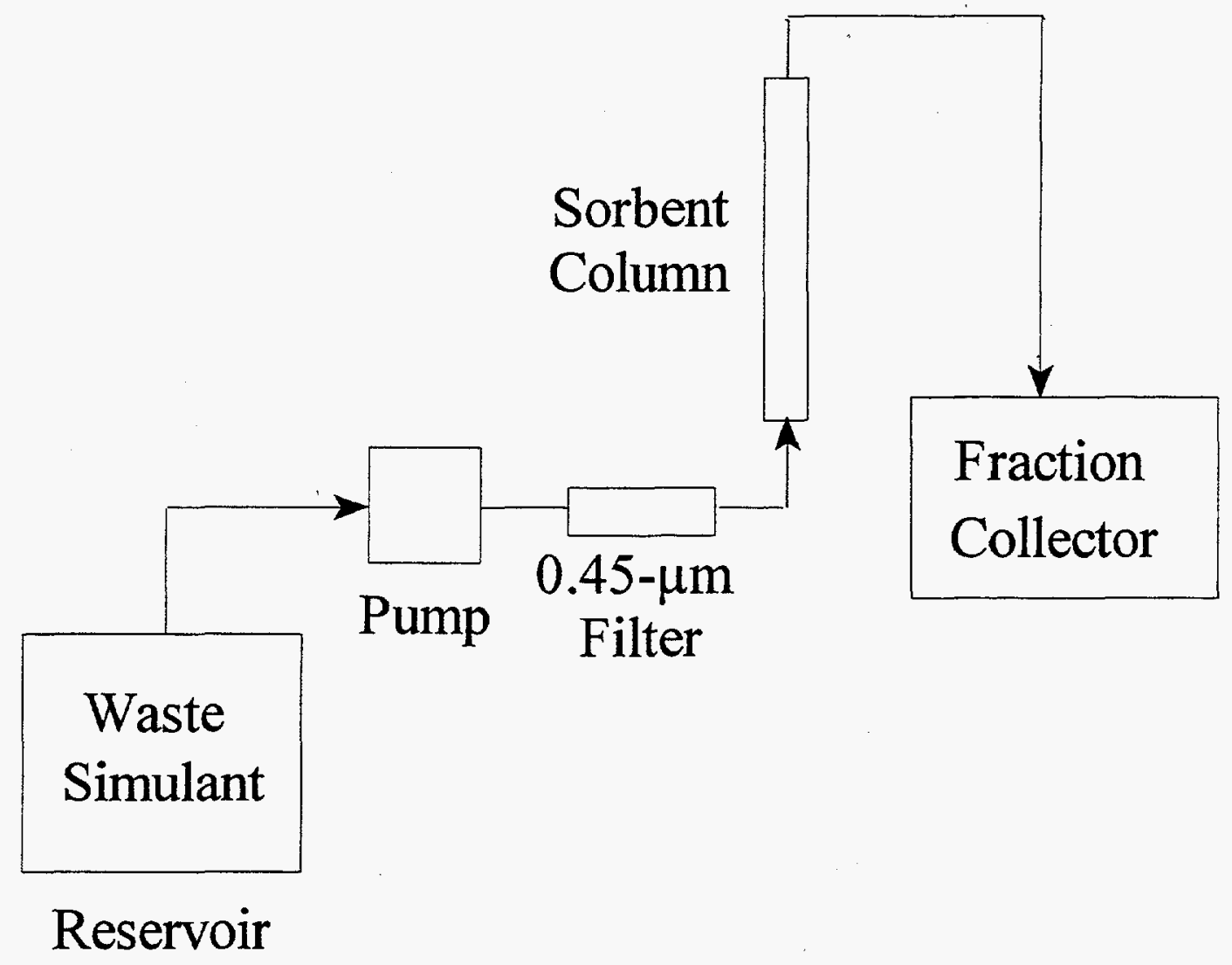

Fig. 1. Flow diagram for small-column test. 
Table 2. Physical characterization of as-received sorbents

\begin{tabular}{lcccc}
\hline Physical parameter & $\begin{array}{c}\text { Chabazite } \\
\text { zeolite }\end{array}$ & R-F resin & $\begin{array}{c}\text { Na nonatitanate } \\
\text { powder }\end{array}$ & $\begin{array}{c}\text { Na nonatitanate } \\
\text { pellet }\end{array}$ \\
\hline Dry density, g/cm & $1.73^{a}$ & $0.7^{b}$ & $0.9^{c}$ & $1.4^{c}$ \\
Pore size, $\AA$ & $4.1-3.7^{a}$ & $\mathrm{NA}^{\mathrm{d}}$ & $\mathrm{NA}$ & $\mathrm{NA}$ \\
Effective pore diameter, $\AA$ & $4.3^{a}$ & $\mathrm{NA}$ & $\mathrm{NA}$ & $\mathrm{NA}$ \\
Total pore volume, $\mathrm{cm}^{3} / \mathrm{g}$ & $0.468^{a}$ & $\mathrm{NA}$ & $\mathrm{NA}$ & $0.108^{e}$ \\
Surface area, $\mathrm{m}^{2} / \mathrm{g}$ & $520.95^{a}$ & $\mathrm{NA}$ & $\mathrm{NA}$ & $52.5^{e}$ \\
MOH hardness & $4-5^{a}$ & $\mathrm{NA}$ & $\mathrm{NA}$ & $\mathrm{NA}$ \\
Crystallinity & $+9 \%^{a}$ & $\mathrm{NA}$ & $\mathrm{NA}$ & $\mathrm{NA}$ \\
Surface moisture, $\mathrm{wt} \%$ & $7.1^{f}$ & $19.1^{f}$ & $7.9^{f}$ & $6.1^{f}$ \\
\hline
\end{tabular}

${ }^{a}$ Cabsorb-ZS500A product literature, GSA Resources, Inc., Cortaro, Ariz.

${ }^{b}$ K. Larsen, Boulder Scientific Co., Mead, Colo., personal communication, June 28, 1996.

${ }^{c}$ I. DeFilippi, formerly of AlliedSignal Research, personal communication, Dec. 7, 1995.

NA $=$ not available.

'S. Yates, I. DeFillippi, M. Andren, R. Gaita, G. Seninara, J. K. Shen, and A. Clearfield, "Novel Ion Exchangers for Strontium and Cesium," DOE Efficient Separations/Processes Technical Information Exchange Meeting, Gaithersburg, Md., Jan. 17, 1996.

${ }^{f}$ Task data acquired in FY 1996. 
The particle size and particle size distribution of a sorbent have significant effects on the efficiency, kinetics, and operational aspects of column performance. ${ }^{8}$ These particular physical parameters are not listed in Table 2 because they are considered by the manufacturers to be product specifications for their sorbents. A $-20 /+50$ mesh cut of the natural chabazite, which is the typical dimension used for ion-exchange column applications, was purchased from the vendor. The $\mathrm{R}-\mathrm{F}$ resin is currently available in a single size range $(-35 /+50$ mesh) and contains less than $10 \%$ fines. The nonatitanate powder received for testing in this task was not selected on the basis of size; however, a specified particle size range can be obtained from AlliedSignal Research. The vendor's data presented in Table 3 for the as-received sample, therefore, may not necessarily represent the size distribution of their typical production nun.

Table 4 presents the dry-particle size distribution of the as-received zeolite and R-F resin. The $-20 /+50$ mesh fraction of each of the dry sorbents was pretreated and used for both batch shaker and column tests. The wet-particle size distributions of the sodium-modified zeolite and water-washed resin, which are also included in Table 3, more accurately reflect the particle size of the sorbents during testing. Sieve analysis ${ }^{9}$ was used to determine both dry- and wet-particle size distributions. The prepared sorbents were added as a water slurry to the sieves; water was then allowed to flow through the sieves to size the wet sorbents. Finally, the sieved fractions of the wet sorbents were air dried to determine the weight distribution of each fraction.

Results of the sieve analysis indicated that the dry, as-received zeolite contained $19 \mathrm{wt} \%$ fines. Approximately $59 \%$ of the as-received resin was finer than the stated $-35 /+50$ mesh range. The average dry particle sizes of the combined $-20 /+50$ fractions of the as-received zeolite and resin were $536 \pm 149$ and 362 $\pm 18 \mu \mathrm{m}$, respectively. Approximately $2 \%$ fines was produced when either of the sorbents was pretreated. The average wet-particle sizes of the pretreated zeolite and resin were $575 \pm 156$ and $474 \pm 73 \mu \mathrm{m}$, respectively. The difference between the average particle size of the dry and wet forms of the zeolite and the resin indicated that the volume of the two sorbents swelled by factors of 1.23 and 2.24 , respectively. The volume change observed with the wet resin agrees well with the vendor's data, in which the density of the resin decreased by a factor of 2.25 once the resin was wetted.

The wet-particle size distribution of the nonatitanate powder, as supplied by AlliedSignal Research staff, is included in Table 3. In-house instrumentation was not available to determine the dry-particle size distribution of the fine powder.

Both size distribution and particle swelling play significant roles in the dispersion observed in a breakthrough curve and in the charging and discharging of a column. As indicated by the smaller coefficient of variation for the average particle size measurement, column dispersion attributed to the variation in particle size is expected to be less for the resin than for the zeolite. However, this conclusion must be 
Table 3. Volume distribution of nonatitanate powder in water (lot 8212-94-3) ${ }^{a}$

\begin{tabular}{lcccccc}
\hline $\begin{array}{l}\text { Distribution, } \\
\text { vol \% }\end{array}$ & 10 & 25 & 50 & 75 & 90 & Average \\
\hline Size, $\mu \mathrm{m}$ & 65.33 & 38.58 & 12.25 & 2.607 & 0.585 & 24.64 \\
\hline${ }^{a}$ S. Yates, AlliedSignal Research, private communication, Oct. 6, 1995.
\end{tabular}

Table 4. Particle size distribution of sorbents tested to date

\begin{tabular}{|c|c|c|c|c|c|}
\hline \multirow{2}{*}{$\begin{array}{l}\text { U.S. sieve } \\
\text { range } \\
\text { (mesh) }\end{array}$} & \multirow[t]{2}{*}{$\begin{array}{c}\text { Particle size } \\
(\mu \mathrm{m})\end{array}$} & \multicolumn{2}{|c|}{ Dry-weight distribution (\%) } & \multicolumn{2}{|c|}{ Wet-weight distribution (\%) } \\
\hline & & $\begin{array}{c}\text { Zeolite, } \\
\text { as-received } \\
\end{array}$ & $\begin{array}{l}\mathrm{R}-\mathrm{F} \text { resin, } \\
\text { as-received }\end{array}$ & $\begin{array}{c}\text { Zeolite, } \\
\text { NaCl-washed }\end{array}$ & $\begin{array}{c}\text { R-F resin, }{ }^{a} \\
\text { water-washed }\end{array}$ \\
\hline+20 & +840 & 0.30 & 0.0026 & 0.00 & 0.00 \\
\hline$-20 /+30$ & $-840 /+590$ & 29.77 & 0.0289 & 50.97 & 1.45 \\
\hline$-30 /+40$ & $-590 /+420$ & 25.24 & 0.4 & 26.09 & 77.11 \\
\hline$-40 /+50$ & $-420 /+300$ & 25.63 & 39.73 & 20.70 & 19.34 \\
\hline$-50 /+60$ & $-297 /+250$ & & & 0.79 & 0.67 \\
\hline-60 & -250 & & & 1.45 & 1.43 \\
\hline$-50 /+80$ & $-300 /+212$ & 19.06 & 32.82 & & \\
\hline$-80 /+100$ & $-177 /+149$ & & 24.81 & & \\
\hline+100 & -149 & & 1.14 & & \\
\hline \multicolumn{2}{|c|}{ Average size, $\mu \mathrm{m}$} & 484 & 231 & 575 & 474 \\
\hline \multicolumn{2}{|c|}{ Std. dev., $\mu \mathrm{m}$} & 223 & 47 & 156 & 73 \\
\hline
\end{tabular}


tempered by the fact that the resin particle radius is much more dependent on solution composition than that of the zeolite. Therefore, the actual variation of resin particle size under normal column operation will probably be greater, due to fluctuations in the feed stream composition, than is obvious from the data presented in Table 4 (i.e., data that were obtained under conditions of constant solution composition).

\subsection{CHEMICAL CHARACTERIZATION OF SORBENTS}

\subsubsection{Cationic Metal Content}

The cationic metal contents of the various sorbents are presented in Table 5. Zeolite data are quoted from product literature supplied by GSA Resources, Inc. The metal content of the R-F resin (lot BSC-187210) was determined in-house by placing 0.1 -g resin samples in platinum crucibles and dry-ashing the material in a muffle furnace. A temperature of $700^{\circ} \mathrm{C}$ was required to fully decompose the resin. The remaining ash represented 30.6 and $20.8 \mathrm{wt} \%$ of the original weight of the as-received and water-washed resin, respectively. The ash was dissolved in ultrapure nitric acid and submitted for analysis by inductively coupled plasma (ICP) spectrometry. Results indicated that the as-received resin contained $28 \mathrm{wt} \%$ potassium, $0.03 \mathrm{wt} \%$ sodium, $0.001 \mathrm{wt} \%$ calcium, and $0.0002 \mathrm{wt} \%$ magnesium. Water-washed resin, which was used to determine sorption characteristics in batch tests, was prepared by rinsing the as-received resin 5 times with 100 volumes of ultrapure water. Pretreatment appeared to remove one-half of the potassium in the resin, as seen from the cationic content of the final water-washed resin: $17 \mathrm{wt} \%$ potassium, $0.015 \mathrm{wt} \%$ sodium, $0.0002 \mathrm{wt} \%$ calcium, and $0.0006 \mathrm{wt} \%$ magnesium. The ICP results show that $1 \mathrm{~kg}$ of the dry, pretreated resin contained approximately 4400 meq and 6.7 meq of potassium and sodium, respectively. The calcium and magnesium contents in the dry resin were insignificant compared with those present in the wastewater simulant. Therefore, the resin contribution of these latter two elements does not need to be considered in determining nuclide sorption $\mathrm{K}_{\mathrm{d}} \mathrm{s}$.

The cationic content of the sodium nonatitanate powder (lot 8212-92) was determined in-house by dissolving the powder in boiling ultrapure sulfuric acid. Results obtained by ICP analysis indicated that the as-received nonatitanate contained $23 \mathrm{wt} \%$ sodium. Only traces of magnesium and calcium were observed,

while potassium was not detected. The sodium content was roughly twice the amount that should be present, based on the theoretical composition of sodium nonatitanate; however, the "excess" sodium was not easily removed with water washes. The total sodium content of a nonatitanate sample that had been washed twice with ultrapure water was $21 \mathrm{wt} \%$, suggesting that only $1 \%$ of the "excess" sodium had been removed. 
Table 5. Chemical composition of sorbents

\begin{tabular}{|c|c|c|c|c|c|}
\hline Parameter & $\begin{array}{l}\mathrm{R}-\mathrm{F} \text { resin, } \\
\text { as-received }\end{array}$ & $\begin{array}{c}\text { R-F resin, } \\
\text { water-washed }\end{array}$ & $\begin{array}{c}\text { Nonatitanate } \\
\text { powder, } \\
\text { as-received }\end{array}$ & $\begin{array}{c}\text { Nonatitanate } \\
\text { powder, } \\
\text { water-washed }\end{array}$ & $\begin{array}{c}\text { Zeolite, } \\
\text { as-received }\end{array}$ \\
\hline $\begin{array}{l}\text { Moisture } \\
\text { content, } \\
\text { wt } \%\end{array}$ & 18.8 & $N^{b}$ & 7.93 & NA & 7.71 \\
\hline $\begin{array}{l}\text { Ash } \\
\text { content, } \\
\text { wt } \%\end{array}$ & 30.6 & 20.8 & NA & NA & NA \\
\hline $\mathrm{Na}$ & 0.03 & 0.015 & 23 & 21 & 6.17 \\
\hline $\mathrm{K}$ & 28 & 17 & Trace & Trace & 0.93 \\
\hline $\mathrm{Mg}$ & 0.0002 & 0.0006 & Trace & Trace & 0.45 \\
\hline $\mathrm{Ca}$ & 0.001 & 0.0002 & Trace & Trace & 0.19 \\
\hline $\mathrm{Al}$ & NA & NA & NA & NA & 13.33 \\
\hline $\mathrm{Si}$ & $\mathrm{NA}$ & $\mathrm{NA}$ & NA & NA & 31.84 \\
\hline
\end{tabular}




\subsubsection{Ion-Exchange Capacity and Ion-Exchange Ratio}

The strontium ion-exchange capacities for sodium-modified zeolite, water-washed R-F resin, and asreceived sodium nonatitanate powder and pellets were determined. Duplicate $0.5-\mathrm{g}$ samples of each sorbent were mixed on a Labquake shaker overnight with $25 \mathrm{~mL}$ of strontium chloride $\left(\mathrm{SrCl}_{2}\right)$ in nanopure water. At the end of a $24-\mathrm{h}$ contact, the samples were centrifuged at 5000 relative centrifugal force (rcf) for $45 \mathrm{~min}$. The equilibrated solution was removed, acidified with ultrapure acid, and submitted for either ICP or AA analysis. The separated sorbents were then contacted with fresh $\mathrm{SrCl}_{2}$ solution for at least $24 \mathrm{~h}$. Multiple contacts were continued until the strontium concentration of each equilibrated solution was equivalent to the initial concentration.

Eleven solution contacts were made with each sorbent to determine the strontium ion-exchange capacity. The initial strontium concentration of the first six contact solutions was $50 \mathrm{ppm}$. At this low concentration, an estimate of the excess counterion present in each sorbent could be determined and accounted for in the calculation of the ion-exchange ratio of strontium. Contacts $7-9$ were made using $0.1 \mathrm{MSrCl}_{2}$; contacts 10-11 used 1.0 $\mathrm{M} \mathrm{SrCl}_{2}$. The higher concentrations of strontium were used to ensure that the sorbents were saturated with strontium so that the total ion-exchange capacity of the sorbents could be determined.

Results of the strontium ion-exchange study are presented in Tables 6-10, in which the amount of strontium sorbed per gram of sorbent is paired with the amount of counterion found in solution for each contact. The excess counterion, introduced during the synthesis of the sorbents, was estimated from the asymptotic approach to a constant ratio of milliequivalents strontium sorbed to milliequivalents of counterion exchanged in the 50-ppm strontium contacts. The constant ion-exchange ratio observed for each of the 50ppm contacts (Tables 6-9) indicated that little extraneous sodium was present in the pretreated zeolite. (This was not true for the new sorbents.) It was estimated that the washed R-F resin contained $0.57 \mathrm{meq} / \mathrm{g}$ excess potassium ion and the nonatitanate powder and pellets contained 0.87 and $0.37 \mathrm{meq} / \mathrm{g}$ excess sodium ion, respectively.

The ion-exchange ratio for each sorbent was estimated from the final 50-ppm contacts, for which it was determined that excess counterion had been removed during previous 50 -ppm strontium contacts. These values are presented in Table 11. The near-unity ion-exchange ratio for the chabazite zeolite demonstrates the well-established fact that 1 eq of alkali cation exchanges for each equivalent of strontium. Strontium sorption on R-F resin was accompanied by an elevation of potassium ion concentration in solution. $\mathrm{The} \mathrm{K} / \mathrm{Sr}$ equivalent exchange ratio for the R-F resin was 1.7 ; no other cation of significance was observed in the equilibrium solutions. The exact nature of strontium affinity on the resin is unknown. 
Table 6. Strontium ion exchange on sodium-modified chabazite zeolite $(0.5 \mathrm{~g})$

\begin{tabular}{clll}
\hline Contact & $\begin{array}{c}\text { Contact } \\
\text { solution }\end{array}$ & $\begin{array}{c}\text { Sr sorbed } \\
(\mathrm{meg} / \mathrm{g})\end{array}$ & $\begin{array}{c}\text { Na released } \\
(\mathrm{meq} / \mathrm{g})\end{array}$ \\
\hline 1 & $50 \mathrm{ppm} \mathrm{Sr}$ & 0.0546 & 0.0573 \\
2 & $50 \mathrm{ppm} \mathrm{Sr}$ & 0.0544 & 0.0551 \\
3 & $50 \mathrm{ppm} \mathrm{Sr}$ & 0.0545 & 0.0536 \\
4 & $50 \mathrm{ppm} \mathrm{Sr}$ & 0.0544 & 0.0508 \\
5 & $50 \mathrm{ppm} \mathrm{Sr}$ & 0.0544 & 0.050 \\
6 & $50 \mathrm{ppm} \mathrm{Sr}$ & 0.0543 & 0.0484 \\
7 & $0.1 \mathrm{MSr}$ & 1.99 & 1.42 \\
8 & $0.1 \mathrm{MSr}$ & 0.474 & 0.282 \\
9 & $0.1 \mathrm{MSr}$ & 0 & 0.069 \\
\hline
\end{tabular}

Table 7. Strontium ion exchange on water-washed $R-F$ resin $(0.5 \mathrm{~g})$

\begin{tabular}{cccc}
\hline Contact & $\begin{array}{c}\text { Contact } \\
\text { solution }\end{array}$ & $\begin{array}{c}\text { Sr sorbed } \\
(\mathrm{meq} / \mathrm{g})\end{array}$ & $\begin{array}{c}\text { K released } \\
(\mathrm{meq} / \mathrm{g})\end{array}$ \\
\hline 1 & $50 \mathrm{ppm} \mathrm{Sr}$ & 0.0607 & 0.583 \\
2 & $50 \mathrm{ppm} \mathrm{Sr}$ & 0.0605 & 0.261 \\
3 & $50 \mathrm{ppm} \mathrm{Sr}$ & 0.0605 & 0.123 \\
4 & $50 \mathrm{ppm} \mathrm{Sr}$ & 0.0605 & 0.116 \\
5 & $50 \mathrm{ppm} \mathrm{Sr}$ & 0.0605 & 0.109 \\
6 & $50 \mathrm{ppm} \mathrm{Sr}$ & 0.0604 & 0.190 \\
7 & $0.1 \mathrm{MSr}$ & 2.76 & 2.25 \\
8 & $0.1 \mathrm{MSr}$ & 0.312 & 0.180 \\
9 & $0.1 \mathrm{MSr}$ & 0 & 0.025 \\
\hline
\end{tabular}


Table 8. Strontium ion exchange on as-received nonatitanate powder $(0.5 \mathrm{~g})$

\begin{tabular}{cccc}
\hline Contact & $\begin{array}{c}\text { Contact } \\
\text { solution }\end{array}$ & $\begin{array}{c}\text { Sr sorbed } \\
(\mathrm{meq} / \mathrm{g})\end{array}$ & $\begin{array}{c}\text { Na released } \\
(\mathrm{meg} / \mathrm{g})\end{array}$ \\
\hline 1 & $50 \mathrm{ppm} \mathrm{Sr}$ & 0.0552 & 0.85 \\
2 & $50 \mathrm{ppm} \mathrm{Sr}$ & 0.0549 & 0.144 \\
3 & $50 \mathrm{ppm} \mathrm{Sr}$ & 0.0550 & 0.100 \\
4 & $50 \mathrm{ppm} \mathrm{Sr}$ & 0.0549 & 0.0844 \\
5 & $50 \mathrm{ppm} \mathrm{Sr}$ & 0.0550 & 0.0755 \\
6 & $50 \mathrm{ppm} \mathrm{Sr}$ & 0.0549 & 0.0752 \\
7 & $0.1 M \mathrm{Sr}$ & 3.45 & 2.41 \\
8 & $0.1 M \mathrm{Sr}$ & 0.373 & 0.207 \\
9 & $0.1 M \mathrm{Sr}$ & 0.159 & 0.0321 \\
\hline
\end{tabular}

Table 9. Strontium ion exchange on as-received nonatitanate pellet $(0.5 \mathrm{~g})$

\begin{tabular}{cccc}
\hline Contact & $\begin{array}{c}\text { Contact } \\
\text { solution }\end{array}$ & $\begin{array}{c}\text { Sr sorbed } \\
\text { (meq/g) }\end{array}$ & $\begin{array}{c}\text { Na released } \\
(\mathrm{meg} / \mathrm{g})\end{array}$ \\
\hline 1 & $50 \mathrm{ppm} \mathrm{Sr}$ & 0.0553 & 0.397 \\
2 & $50 \mathrm{ppm} \mathrm{Sr}$ & 0.0551 & 0.169 \\
3 & $50 \mathrm{ppm} \mathrm{Sr}$ & 0.0553 & 0.0895 \\
4 & $50 \mathrm{ppm} \mathrm{Sr}$ & 0.0552 & 0.0790 \\
5 & $50 \mathrm{ppm} \mathrm{Sr}$ & 0.0552 & 0.0687 \\
6 & $50 \mathrm{ppm} \mathrm{Sr}$ & 0.0549 & 0.0788 \\
7 & $0.1 M \mathrm{Sr}$ & 1.50 & 1.16 \\
8 & $0.1 M \mathrm{Sr}$ & 0.3044 & 0.130 \\
9 & $0.1 M \mathrm{Sr}$ & 0.103 & 0.0737 \\
\hline
\end{tabular}


Table 10. Cesium ion exchange on water-washed R-F resin $(0.05 \mathrm{~g})$

\begin{tabular}{cccc}
\hline Contact & $\begin{array}{c}\text { Contact } \\
\text { solution }\end{array}$ & $\begin{array}{c}\text { Cs sorbed } \\
(\mathrm{meg} / \mathrm{g})\end{array}$ & $\begin{array}{c}\text { K released } \\
(\mathrm{meq} / \mathrm{g})\end{array}$ \\
\hline 1 & $50 \mathrm{ppm} \mathrm{Cs}$ & 0.179 & 0.446 \\
2 & $50 \mathrm{ppm} \mathrm{Cs}$ & 0.105 & 0.291 \\
3 & $50 \mathrm{ppm} \mathrm{Cs}$ & 0.0921 & 0.265 \\
4 & $50 \mathrm{ppm} \mathrm{Cs}$ & 0.0810 & 0.250 \\
5 & $50 \mathrm{ppm} \mathrm{Cs}$ & 0.0537 & 0.259 \\
6 & $50 \mathrm{ppm} \mathrm{Cs}$ & 0.0600 & 0.217 \\
7 & $0.1 \mathrm{MCs}$ & -521 & 1.76 \\
\hline
\end{tabular}

Table 11. Ion-exchange capacities of sorbents

\begin{tabular}{lccc}
\hline Sorbent & $\begin{array}{c}\text { Major } \\
\text { counter } \\
\text { cation }\end{array}$ & $\begin{array}{c}\text { Total ion- } \\
\text { exchange } \\
\text { capacity (meq/g) }\end{array}$ & $\begin{array}{c}\text { Average ion- } \\
\text { exchange ratio } \\
\text { for 50-ppm contacts }\end{array}$ \\
\hline $\begin{array}{l}\text { Sodium-modified } \\
\text { chabazite }\end{array}$ & $\mathrm{Na}^{+}$ & 2.2 & $0.96 \pm 0.06 \mathrm{meq} \mathrm{Na} / \mathrm{meq} \mathrm{Sr}$ \\
R-F resin & $\mathrm{K}^{+}$ & 3.2 & $2.2 \pm 0.1 \mathrm{meq} \mathrm{K} / \mathrm{meq} \mathrm{Sr}$ \\
R-F resin & $\mathrm{K}^{+}$ & 1.7 & $1.0 \pm 0.1 \mathrm{meq} \mathrm{K} / \mathrm{meq} \mathrm{Cs}$ \\
Nonatitanate powder & $\mathrm{Na}^{+}$ & 3.1 & $1.4 \pm 0.1 \mathrm{meq} \mathrm{Na} / \mathrm{meq} \mathrm{Sr}$ \\
Nonatitanate pellets & $\mathrm{Na}^{+}$ & 1.8 & $1.4 \pm 0.1 \mathrm{meq} \mathrm{Na} / \mathrm{meq} \mathrm{Sr}$ \\
\hline
\end{tabular}


Previous loading experiments have indicated that the resorcinol sites have little or no affinity for this ion. ${ }^{10}$ The noninteger ratio of $\mathrm{K} / \mathrm{Sr}$ exchange indicates that perhaps a physical sorption process, in addition to ion exchange, could account for Sr uptake on the resin. Further testing with this sorbent might include anion analysis of equilibrated solutions, which might suggest a possible reaction mechanism for the charge balance between potassium release and strontium sorption on $\mathrm{R}-\mathrm{F}$ resin.

Lehto et al. ${ }^{7}$ found that 1 eq of sodium is exchanged per equivalent of strontium uptake on sodium nonatitanate sorbent. In our studies, tabulated results for both the powder and pellets forms of the nonatitanate indicate a slightly higher exchange ratio. Physical sorption of strontium on the nonatitanate might also account for the fact that the experimental ion-exchange ratio is slightly greater than the theoretical value. However, this conclusion must be viewed with the understanding that experimental error is incurred in the calculation as a result of estimates of excess counterion present in both R-F resin and nonatitanate sorbents.

The standard deviation stated with the ion-exchange ratio for each sorbent in Table 10 represents the variation observed in the multiple contacts of a sample with $50 \mathrm{ppm}$ strontium. The variation in the exchange ratio between the 50-ppm and $0.1 \mathrm{M} \mathrm{SrCl}_{2}$ contacts for a given sorbent is considerably larger. The exchange ratio appears to decrease as the concentration of strontium in contacting solution increases, particularly in the case of R-F resin. This behavior may be the result of physical sorption of strontium on the surface of the sorbents.

Two contacts with $0.1 M \mathrm{SrCl}_{2}$ fully loaded all the sorbents with strontium. The cation-exchange capacities for the zeolite and resin are similar to those found in published data for the products (Table 11). The theoretical exchange capacity for the nonatitanate is $4.74 \mathrm{meq} / \mathrm{g}$, based on a molecular formula of $\mathrm{Na}_{4} \mathrm{Ti}_{9} \mathrm{O}_{20} \cdot x \mathrm{H} 2 \mathrm{O}$. However, the experimental results are significantly lower than this value for both forms of the sorbent.

The cesium exchange ratio was also determined for water-washed $R-F$ resin. Because sufficient cesium remained in solutions treated with only $0.05 \mathrm{~g}$ of resin, a more accurate determination of the ion-exchange ratio could be used to estimate the exchange ratio. Cesium sorption data (Table 10) were plotted according to the equation

$$
\left(\mathrm{d} \log \mathrm{Kd}_{\mathrm{M}}\right) /\left(\mathrm{d} \log \left[\mathrm{A}^{\mathrm{m}+}\right]_{\mathrm{aq}}\right)=-\mathrm{n} / \mathrm{m}
$$

where $\mathrm{Kd}_{\mathrm{M}}$ represents the sorption ratio of cesium, $\left[\mathrm{A}^{\mathrm{m}+}\right]_{\mathrm{aq}}$ represents the aqueous concentration of potassium, and $n / m$ signifies the charge ratio of cesium to potassium. ${ }^{11}$ Ideally, this latter value should be one 
in the case of potassium-cesium exchange on the resin. Due to the presence of excess potassium in the sample, the data from the first 50-ppm cesium contact were not included in the determination of the slope of the data line presented in Fig. 2. The calculated slope, based on the remaining five contacts with $50 \mathrm{ppm}$ cesium, is $-1.03 \pm 0.13$. A correlation coefficient of 0.90 reflects the difficulty encountered in determining exchange ratios and capacities in the presence of excess counterion.

The total ion-exchange capacity based on cesium sorption was lower than typical literature values for the R-F resin. As indicated in Table 10, most of the accumulated cesium desorbed from the $0.05 \mathrm{~g}$ of resin when it was contacted with $0.1 M \mathrm{CsCl}_{2}$. Therefore, the total ion-exchange capacity was based only on the quantity of cesium sorbed during the multiple contacts with $50 \mathrm{ppm}$ cesium. The ion-exchange reactions listed in Table 12 take into account the experimental ion-exchange ratios. Neglecting the effects of activity coefficients, the molal equilibrium constant $\left(\mathrm{K}_{\mathrm{eq}}\right)$, also referred to as the molal selectivity coefficient $\left(\mathrm{K}_{\mathrm{B}}^{\mathrm{A}}\right)$, for each of the reactions, can be calculated according to the following general equations:

$$
\mathrm{mM}^{\mathrm{n}+}(\mathrm{aq})+\mathbf{n A ^ { \mathrm { m } + }}(\mathrm{s}) \rightleftharpoons \mathrm{mM}^{\mathrm{n}+}(\mathrm{s})+\mathbf{n A} \mathrm{m}^{\mathrm{m}+}(\mathrm{aq})
$$

and

$$
K_{e q}=\frac{\left[M^{n+}\right]^{m}(s)\left[A^{m+}\right]^{n}(a q)}{\left[M^{n+}\right]^{m}(a q)\left[A^{m+}\right]^{n}(s)},
$$

where $\mathrm{M}$ and $\mathrm{A}$ are ions of charge $\mathrm{n}+$ and $\mathrm{m}+$, respectively. The "aq" indicates the aqueous-phase molality, and the "s" signifies the sorbent molality of a given ion. For trace quantities of $\mathrm{M}^{\mathrm{n}+}$ and an exchanger capacity of $\mathrm{C}$, the amount of $\mathrm{A}^{\mathrm{m+}}$ in the solid (in equivalents) is essentially equivalent to the sorbent capacity.

The equilibrium constants for strontium (and cesium) on each of the sorbents were calculated using the respective experimental ion-exchange ratios and exchange capacities. These values are also presented in Table 12. Values of $\mathrm{K}_{\mathrm{eq}}$ were calculated for samples that had been contacted several times with 50 -ppm strontium solution. The concentration of potassium on the resin is equivalent to the sorbent ion-exchange capacity minus the cumulative amount of strontium sorbed. Sodium concentration in the nonatitanate was similarly calculated. 


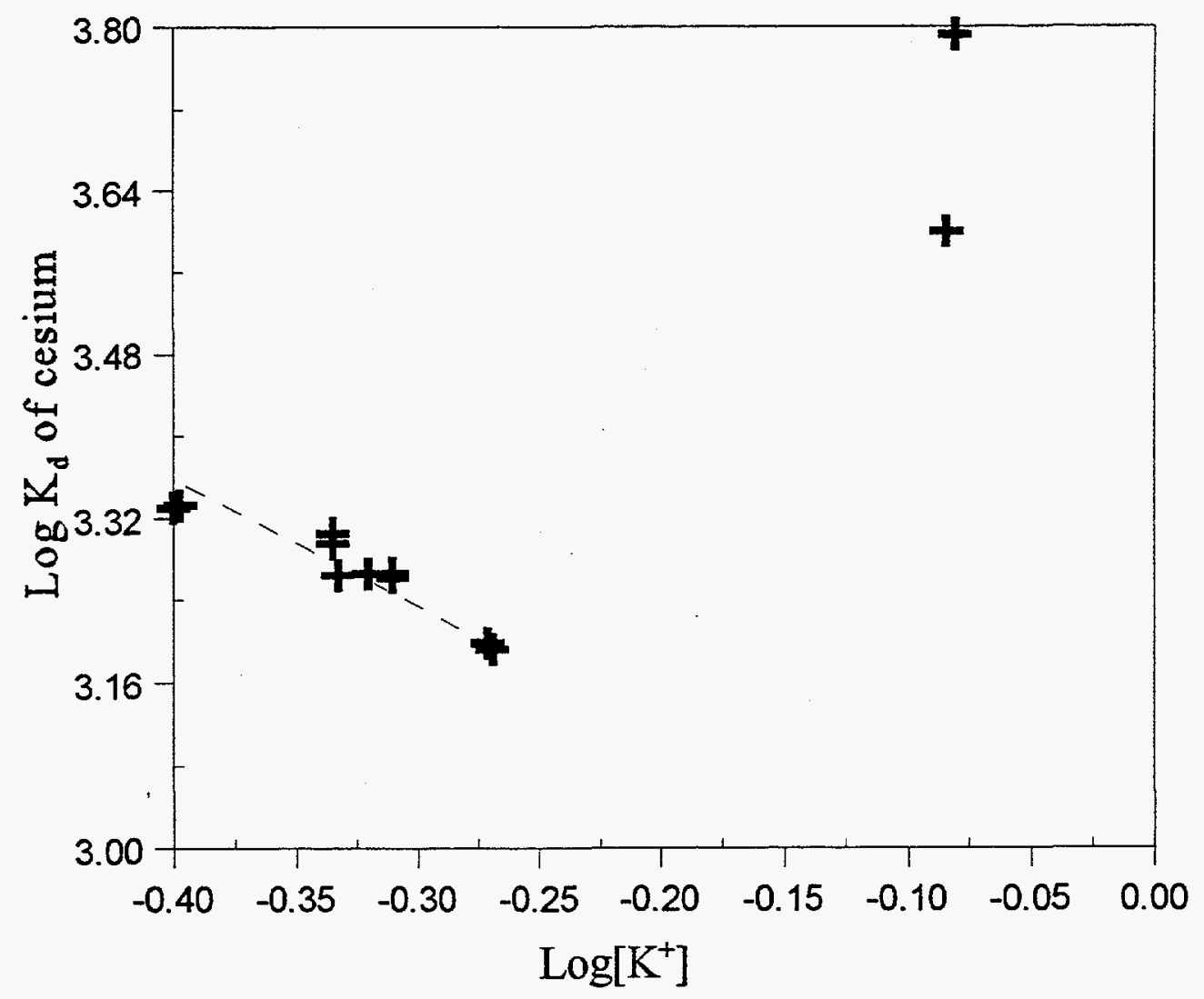

Fig. 2. Determination of cesium ion-exchange ratio on water-washed R-F resin. 
Table 12. Ion-exchange reactions for task sorbents

\begin{tabular}{|c|c|c|}
\hline Sorbent & Exchange reaction & $\begin{array}{l}\text { Molal equilibrium } \\
\text { coefficient, } K_{\text {eq }}\end{array}$ \\
\hline $\begin{array}{l}\text { Sodium-modified } \\
\text { zeolite }\end{array}$ & $\begin{array}{l}2 \mathrm{Na}_{s}^{+}+\mathrm{Sr}^{2+} \rightleftharpoons \mathrm{aq}^{\rightleftarrows} \\
2 \mathrm{Na}^{+}{ }_{\mathrm{aq}}+\mathrm{Sr}^{2+}{ }_{s}\end{array}$ & $3.3 \pm 1.1$ \\
\hline $\begin{array}{l}\text { Water-washed R-F } \\
\text { resin }\end{array}$ & $\begin{array}{l}3.8 \mathrm{~K}_{\mathrm{s}}^{+}+\mathrm{Sr}^{2+} \rightleftharpoons \mathrm{aq}^{2+} \\
3.8 \mathrm{~K}_{\mathrm{aq}}^{+}+\mathrm{Sr}^{2+}{ }_{s}\end{array}$ & $19 \pm 6$ \\
\hline $\begin{array}{l}\text { Water-washed R-F } \\
\text { resin }\end{array}$ & $\begin{array}{l}\mathrm{K}_{\mathrm{s}}^{+}+\mathrm{Cs}_{\mathrm{aq}}^{+} \rightleftharpoons \\
\mathrm{K}_{\mathrm{aq}}^{+}+\mathrm{Cs}_{\mathrm{s}}^{+}\end{array}$ & $0.13 \pm 0.05$ \\
\hline $\begin{array}{l}\text { Water-washed sodium } \\
\text { nonatitanate }\end{array}$ & $\begin{array}{l}2 \mathrm{Na}_{\mathrm{s}}^{+}+\mathrm{Sr}^{2+} \underset{\mathrm{aq}}{\rightleftarrows} \\
2 \mathrm{Na}^{+}{ }_{\mathrm{aq}}+\mathrm{Sr}_{\mathrm{s}}^{2+}\end{array}$ & $\begin{array}{c}3.9 \pm 1.8 \text { (powder) } \\
13 \pm 5 . \text { (pellets) }\end{array}$ \\
\hline
\end{tabular}




\subsubsection{Estimation of Particle and Film Diffusion Coefficients}

The time required to obtain an equilibrium concentration in batch shaker tests was determined for each of the sorbents tested. Data from these tests were used to ensure that batch test results were obtained under equilibrium conditions. Additionally, the time-dependent data were used to estimate the particle and film diffusion coefficients for strontium and cesium in each sorbent. The strontium and cesium sorption rates from the simulated wastewater were determined by mixing a series of samples containing $20 \mathrm{mg}$ of the sorbent in $10 \mathrm{~mL}$ of the traced simulant on a Labquake shaker. The sorption of each nuclide on treated zeolite and R-F resin reached steady state in $24 \mathrm{~h}$ (Fig. 3). Both strontium and cesium sorption on the resin steadily declined with longer contact times. On the basis of these results, a 24-h equilibrium mixing time was used for batch sorption tests with the zeolite and R-F resin.

Equilibrium mixing times were also determined for both the powder and pellet forms of sodium nonatitanate. Maximum strontium sorption on 5 and $20 \mathrm{mg}$ of nonatitanate was observed at contact times of 24 and $10 \mathrm{~h}$, respectively; it was observed at less than $2 \mathrm{~h}$ for 50 - and $100-\mathrm{mg}$ powder samples. As seen in Fig. 3, strontium desorbed from the nonatitanate for contact times greater than the optimum mixing time. The maximum equilibration time for the pelletized form of the nonatitanate was considerably longer. Strontium removal from $10-\mathrm{mL}$ simulant samples was most complete when a pellet was mixed for $500-650 \mathrm{~h}$. Beyond this time, strontium also desorbed from the pellet.

Only sorption data obtained within the first few hours of the mixing studies were used to estimate the diffusion coefficients for each sorbent. The calculations are based on the fractional attainment of nuclide sorption at a given time $(t)$, as compared with the maximum cation sorption observed at equilibrium. The rate of fractional sorption (F) of a cation that is governed by particle diffusion is related to the "diffusional frequency," $\mathrm{B}$, through the equation

$$
\mathrm{Q}_{\mathrm{t}} / \mathrm{Q}_{\mathrm{e}}=\mathrm{F}=1-\left(6 / \mathrm{II}^{2}\right) \sum_{\mathrm{n}=1}^{\infty}\left(1 / \mathrm{n}^{2}\right) \exp \left(-\mathrm{n}^{2} \mathrm{Bt}\right)
$$

where $B=\Pi^{2} D_{p} / r^{2}, r$ is the particle radius, $n$ is an integer, $D_{p}$ is the diffusion of the nuclide through the sorbent, and $Q_{t}$ and $Q_{e}$ are the amounts of exchange at time $t$ and at equilibrium, respectively. ${ }^{12,13}$ Kinetic data for the various sorbents are presented in Figs. 4 and 5. The slope of the kinetic data, in each case, was used to estimate the particle diffusion coefficients presented in Table 13. As has been found in other studies, ${ }^{14,15}$ the particle diffusion coefficient was larger for the organic resin than for the inorganic exchangers. The values of the particle diffusion coefficients determined in the equilibrium mixing experiments were comparable to those observed for sodium-strontium exchange: $1.5 \times 10^{-8} \mathrm{~cm}^{2} / \mathrm{s}$ on 


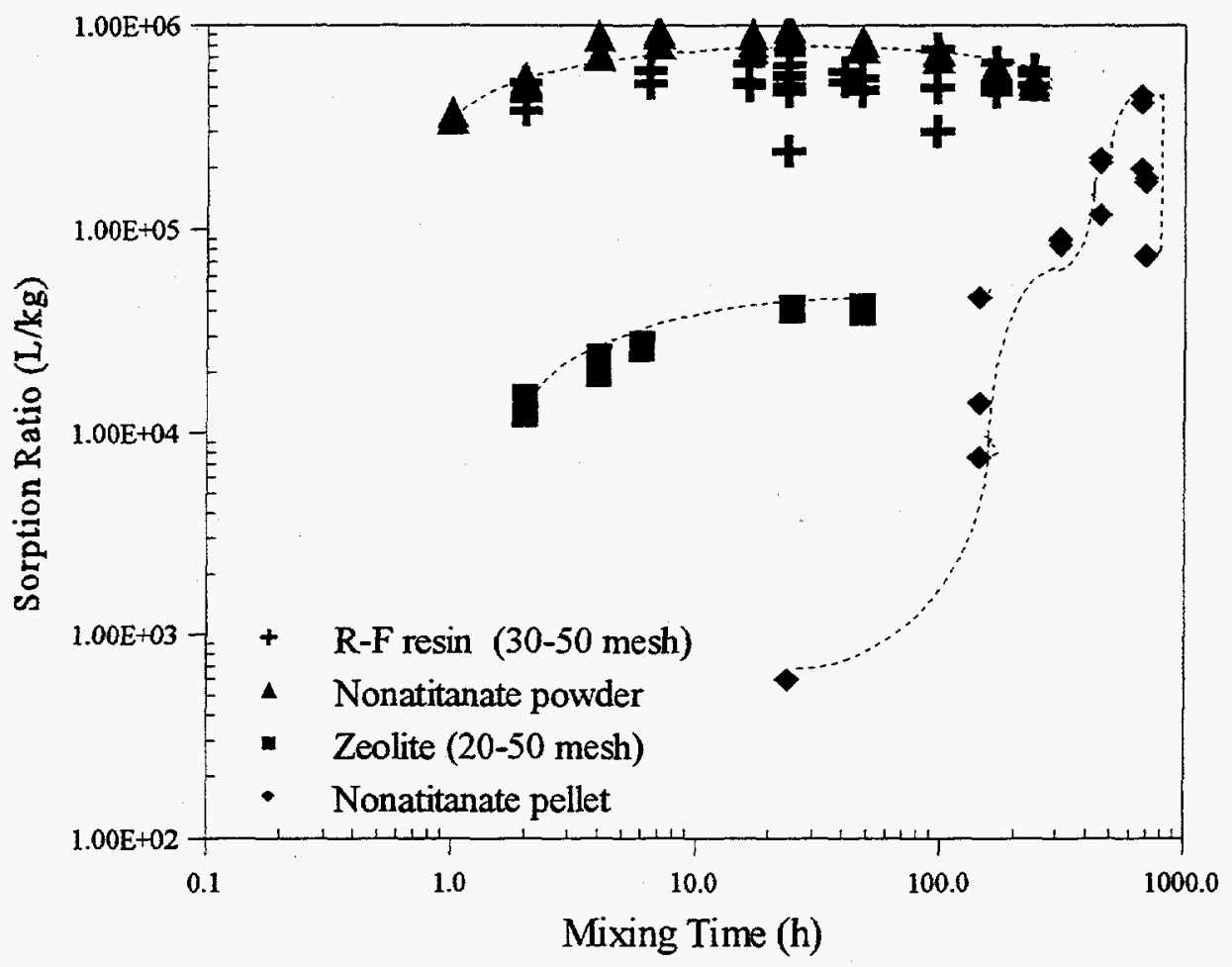

Fig. 3. Strontium equilibration time on $20 \mathrm{mg}$ of sorbent. Test conditions: $20 \mathrm{mg}$ sorbent in $10 \mathrm{~mL}$ of simulant; $0.0228 \mathrm{meq} / \mathrm{L} \mathrm{Sr}$ and 3.23

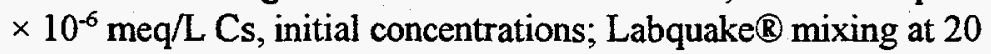
cycles/min; samples centrifuged at $5000 \mathrm{rcf}$ for $30 \mathrm{~min}$ or filtered through a $0.45-\mu \mathrm{m}$-pore nylon membrane. 


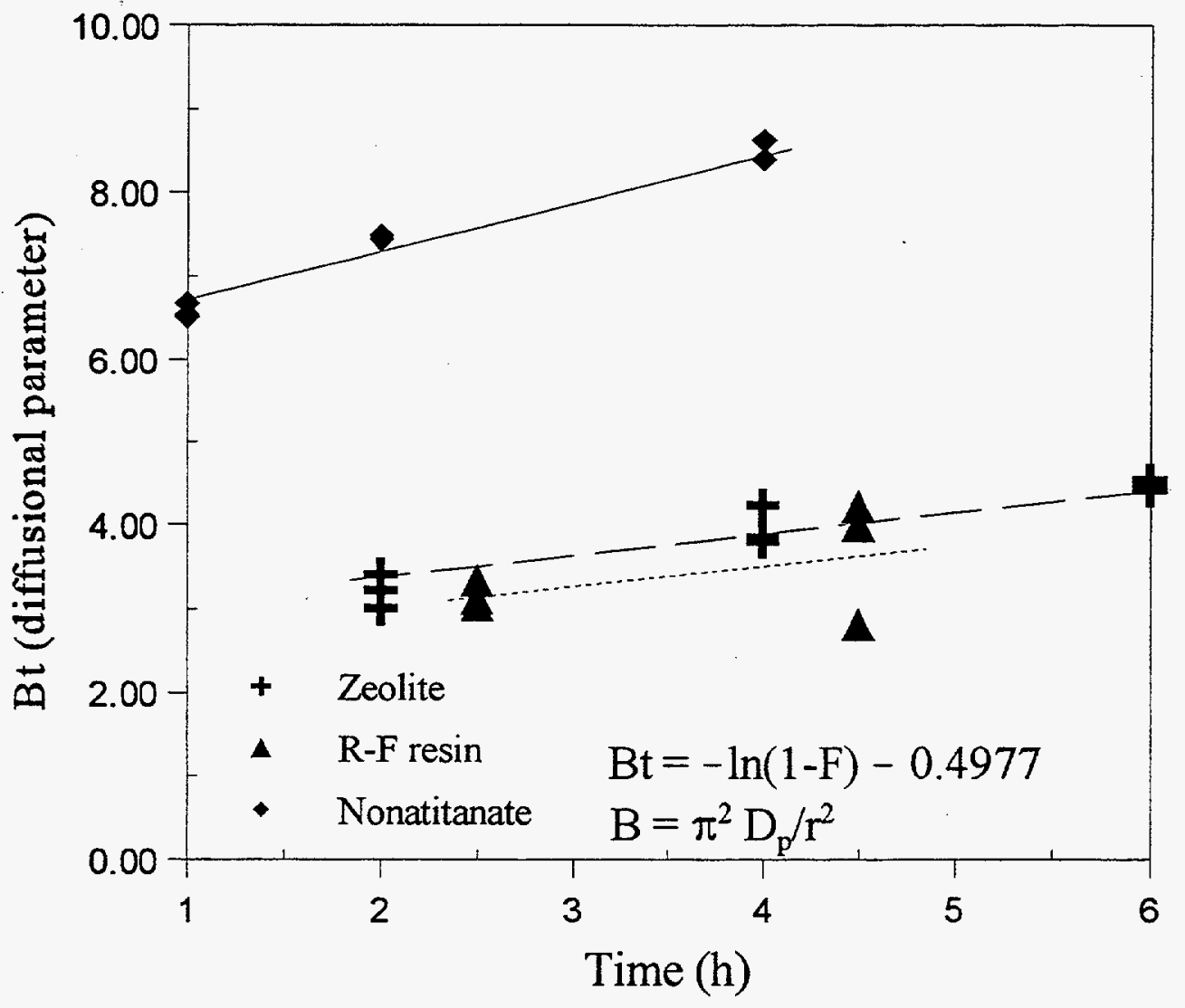

Fig. 4. Calculation of strontium particle diffusion coefficient. Test conditions: $20 \mathrm{mg}$ ( $5 \mathrm{mg}$ for R-F resin) sorbent in $10 \mathrm{~mL}$ of simulant; $0.0228 \mathrm{meq} / \mathrm{L} \mathrm{Sr}(0.00271 \mathrm{meq} / \mathrm{L}$. Sr and no $\mathrm{Cs}$ for sodium nonatitanate) and $3.23 \times 10^{-6} \mathrm{meq} / \mathrm{L} \mathrm{Cs}$, initial concentrations; Labquake $($ mixing at 20 cycles/min; samples centrifuged at $5000 \mathrm{rcf}$ for $30 \mathrm{~min}$ and filtered through a $0.45-\mu \mathrm{m}$-pore nylon membrane. 


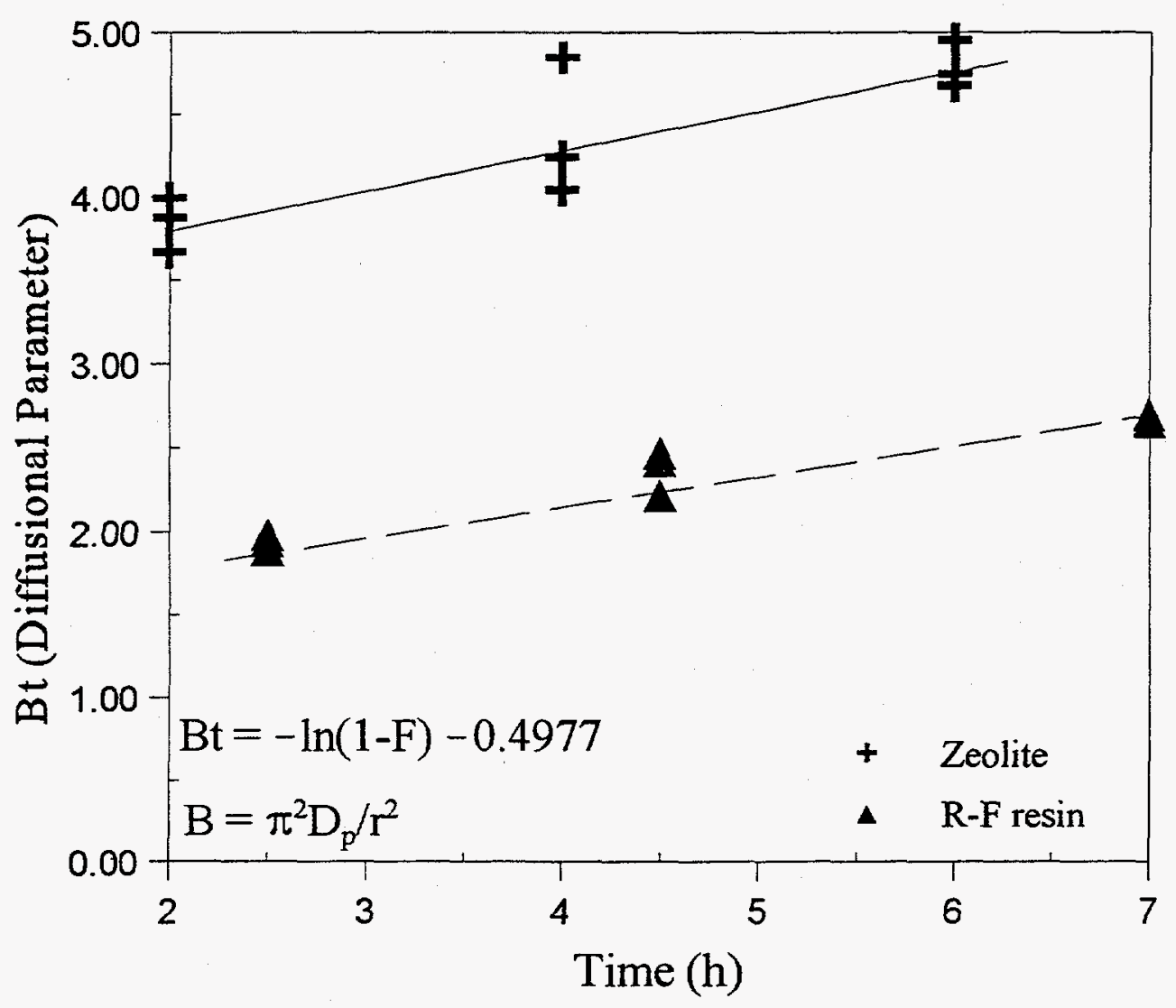

Fig. 5. Calculation of cesium particle diffusion coefficient. Test conditions: $20 \mathrm{mg}$ ( $5 \mathrm{mg}$ for R-F resin) sorbent in $10 \mathrm{~mL}$ of simulant; $0.0228 \mathrm{meq} / \mathrm{L} \mathrm{Sr}$ and $3.23 \times 10^{-6} \mathrm{meq} / \mathrm{L} \mathrm{Cs}$, initial concentrations;

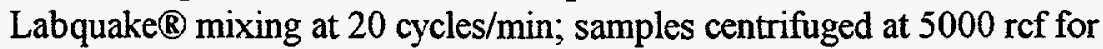
$30 \mathrm{~min}$ and filtered through a $0.45-\mu \mathrm{m}$-pore nylon membrane. 
zeolite, ${ }^{16} 3.4 \times 10^{-8} \mathrm{~cm}^{2} / \mathrm{s}$ on Dowex 50-X8 resin, ${ }^{13}$ and $2.3 \times 10^{-9} \mathrm{~cm}^{2} / \mathrm{s}$ on nonatitanate pellets. ${ }^{17}$ Cesium exchange rates for inorganic exchangers were noted in previous studies in which the particle diffusion coefficients were $1.1 \times 10^{-8} \mathrm{~cm}^{2} / \mathrm{s}$ on synthetic zeolite, ${ }^{18} 10^{-9} \mathrm{~cm}^{2} / \mathrm{s}$ on chabazite zeolite, ${ }^{19}$ and $2.1 \times 10^{-8}$ $\mathrm{cm}^{2} / \mathrm{s}$ on hydrous titanium dioxide.

For the process to be totally governed by particle diffusion, the Bt-vs-t plot should be linear and pass through the origin of the plot. Under the mixing conditions for the equilibrium batch study, it appears that both particle and film diffusion play a role in nuclide uptake. An estimate of the film diffusion coefficients $\left(D_{\hat{v}}\right)$ under these testing conditions was made, using the following equation:

$$
Q_{t} / Q_{e}=F=1-\exp \left[-\frac{3 D_{c}\left(V_{S} C_{S}+V C\right)}{r \delta C_{S} V}\right]
$$

where $V_{S}$ is the volume of the sorbent, $C_{S}$ is the concentration of the counterion in the sorbent (equivalent to the sorbent capacity), $\mathrm{V}$ is the volume of sample solution, and $\mathrm{C}$ is the nuclide concentration remaining in solution. Again, $r$ is the particle radius and $t$ represents the time at which the solution was sampled. ${ }^{20}$ The term $\delta$ represents the solution film thickness around the particle in which the exchange is taking place. It can be calculated according to the following equation:

$$
\delta \approx 0.2 \mathrm{r} /(1+70 \mathrm{rv})
$$

where $v$ represents the solution velocity. The slope of the kinetic data was used to calculate $D_{f} ;$ calculated values for the film diffusion coefficients for the various sorbents are presented in Table 14. In general, film diffusion coefficients for organic resins are typically on the order of $10^{-5} \mathrm{~cm}^{2} / \mathrm{s}$. Comparable values from other studies include $2.0 \times 10^{-7} \mathrm{~cm}^{2} / \mathrm{s}$ for strontium on nonatitanate pellets and $10^{-5} \mathrm{~cm}^{2} / \mathrm{s}$ for cesium sorption on chabazite zeolite. ${ }^{\text {11 }}$

The experimental data quoted in these equilibration experiments provide an estimate of the pore and film diffusion coefficients. However, film diffusion coefficients appear to be lower than typical values observed in dilute aqueous media for chabazite zeolite. Pore diffusion data would more accurately be observed in a stirred-vessel experiment wherein the contribution by film diffusion to the determination would be negligible. The stirred-vessel experiment should be performed in both binary and multicomponent systems to substantiate the estimates of these coefficients obtained from the above Labquake mixer experiments. 
Table 13. Estimation of particle $\left(D_{p}\right)$ and film diffusion $\left(D_{r}\right)$ coefficients

\begin{tabular}{llllll}
\hline & \multicolumn{2}{c}{ Estimated $\mathrm{D}_{\mathrm{p}}\left(\mathrm{cm}^{2} / \mathrm{s}\right)$} & & \multicolumn{2}{c}{ Estimated $\mathrm{D}_{\mathrm{f}}\left(\mathrm{cm}^{2} / \mathrm{s}\right)$} \\
\cline { 2 - 3 } \cline { 5 - 6 } Sorbent & Strontium & Cesium & & Strontium & Cesium \\
\hline Zeolite & $7.4 \times 10^{-9}$ & $5.5 \times 10^{-9}$ & & $2.1 \times 10^{-7}$ & $4.7 \times 10^{-7}$ \\
$\begin{array}{l}\text { R-F resin } \\
\text { Sodium } \\
\text { nonatitanate } \\
\text { powder }\end{array}$ & $1.0 \times 10^{-8}$ & $2.6 \times 10^{-9}$ & & $1.5 \times 10^{-7}$ & $3.4 \times 10^{-7}$ \\
\hline
\end{tabular}

Table 14. Pretreatment procedures for sorbents

\begin{tabular}{|c|c|c|c|}
\hline Sorbent & $\begin{array}{l}\text { Pretreatment } \\
\text { procedure }\end{array}$ & Purpose & Effect \\
\hline Chabazite zeolite & $\begin{array}{l}\text { Sieved; } 2 M \mathrm{NaCl} \text { wash; } \\
\mathrm{H}_{2} \mathrm{O} \text { wash; air dry }\end{array}$ & To remove natural $\mathrm{Sr}$ & $\begin{array}{l}\text { Increases sorption } \\
\text { capacity } 30 \%\end{array}$ \\
\hline R-F resin & $\begin{array}{l}\text { Sieved; five } 1: 10(v / v) \\
\mathrm{H}_{2} \mathrm{O} \text { washes; air dry }\end{array}$ & $\begin{array}{l}\text { To remove } \mathrm{K}^{+} \text {and } \\
\text { resin leachables }\end{array}$ & $\begin{array}{l}\text { Increases } \\
\text { sorption at low } \\
{[\mathrm{Sr}],[\mathrm{Cs}]}\end{array}$ \\
\hline $\begin{array}{l}\text { Nonatitanate } \\
\text { powder }\end{array}$ & $\begin{array}{l}\text { Two } 1: 10(v / v) \\
\mathrm{H}_{2} \mathrm{O} \text { washes; air dry; } \\
\text { dry at } 104^{\circ} \mathrm{C}\end{array}$ & To remove excess $\mathrm{Na}^{+}$ & $\begin{array}{l}\text { Increases } \\
\text { sorption at low } \\
{[\mathrm{Sr}]}\end{array}$ \\
\hline Nonatitanate pellets & Used as received & & \\
\hline
\end{tabular}




\subsubsection{Sorbent Pretreatment Requirements}

In a continuation of efforts begun in FY 1995, the optimum performance of each sorbent was evaluated as a function of pretreatment strategies. Strontium and cesium removal was observed after the sorbents had been (1) washed with ultrapure water; (2) washed with $2 \mathrm{M} \mathrm{NaCl}$ solution, then rinsed with water;

(3) washed with $1 \mathrm{M} \mathrm{HCl}$, then rinsed with water; and finally, (4) washed with simulant that contained neither strontium or cesium. Table 15 summarizes the cumulative task data for pretreatment methods found most suitable for each sorbent. Zeolite performance was enhanced when the natural strontium was removed using a saline wash. Excess potassium and leachable organics were best removed with multiple water rinses. Recent studies with nonatitanate found that the sorbent contains free sodium ion that should be removed with water for maximum sorption capacity.

\section{SORPTION CHARACTERISTICS}

\subsection{SORPTION CHARACTERISTICS OF CHABAZITE ZEOLITE}

\subsubsection{Zeolite Batch Studies}

Most of the data for the baseline zeolite sorbent were acquired during FY 1994-1995. Sorption data for the pretreated zeolite were fit to an empirical equation, referred to as a Freundlich sorption model. These data were approximately linear when the log value of the equilibrium strontium solution concentration, in millequivalents per liter, was plotted versus the log value of strontium sorbed on the zeolite, in milliequivalents per kilogram. The slope of the Freundlich relationship was 0.74 , and the intercept was 3.4; the correlation coefficient for a linear fit was 0.98 . (The slight deviation from linearity reflects the influence of concomitant cations competing for sorption sites at low strontium concentration.) Thus, the empirical equation defining strontium sorption from wastewater simulant on pretreated zeolite is

$$
\log \mathrm{Q}_{\mathrm{e}}=\log \mathrm{K}_{\mathrm{F}}+1 / \mathrm{n} \log \mathrm{C}
$$

or

$$
\log Q_{e}=3.4+0.74 \log C \text {, }
$$

where $Q_{e}$ is the quantity of strontium on the sorbent, in milliequivalents per kilogram at equilibrium; $K_{F}$ is the Freundlich constant; $\mathrm{C}$ is the equilibrium concentration in solution, in units of milliequivalents per liter; and $1 / n$ is the sorption intensity. ${ }^{21}$ Since the distribution coefficient, $K_{d}$, is equivalent to

$$
K_{d}=Q_{e} / C,
$$


Table 15. Conditions and parameters for R-F resin column study

Column operating conditions

Bed volume, $\mathrm{mL}$ 3.85

Bed height, $\mathrm{cm}$

4.9

Dry resin weight, $\mathrm{g}$

1.4

Superficial velocity, $\mathrm{cm} / \mathrm{h}$

94

Calculated column parameters

Strontium

Cesium

Distribution coef., L/kg

1,550

33,000

Column distrib. coef., $\mathrm{L} / \mathrm{L}$

400

12,000

Saturation capacity, meq/g

$4.3 \times 10^{-3}$

$8.5 \times 10^{-5}$

Degree of bed saturation, \%

65

20

Liq. mass transfer coef., $\mathrm{K}_{1} \mathrm{a}, \mathrm{L} / \mathrm{h}$

0.15

0.0019

No. theoretical mass transfer plates

2.9

1.2

Height of theoretical plate, $\mathrm{cm}$

1.7

Eddy diffusion height, $\mathrm{cm}$

0.08

0.08

Particle diffusion height, $\mathrm{cm}$

2.1

0.10

Film diffusion height, $\mathrm{cm}^{a}$

${ }^{a} \mathrm{Calculation}$ based on the "best fit" column values of $1 \times 10^{-5} \mathrm{~cm}^{2} / \mathrm{s}$ and $4 \times 10^{-6} \mathrm{~cm}^{2} / \mathrm{s}$ for the strontium and cesium film diffusion coefficients, respectively. 
$K_{d} / C$ can be substituted for $Q_{e}$ in Eq. (7). The value of $K_{d}$ can then be calculated as a function of the Freundlich constants:

$$
\mathrm{K}_{\mathrm{d}}=2500 \times \mathrm{C}^{-0.26}
$$

The cesium sorption data were also fit to the empirical Freundlich sorption model; the slope of the curve was 0.98 , and the intercept was 4.75 . Cesium data fit the Freundlich model better than those for strontium, as demonstrated by a higher linear correlation coefficient of 0.996 . Thus, the comparable equation defining cesium sorption on pretreated zeolite is

$$
K_{d}=56,000 \times C^{-0.02}
$$

A thermodynamic-based multicomponent ion-exchange equilibrium model developed by Perona predicts the distribution coefficients for both strontium and cesium on chabazite zeolite as a function of the competing cation concentration. ${ }^{22}$ This model has recently been extended to include a pore diffusion model that more accurately predicts the transient uptake rates of cations in multicomponent ion exchange on the zeolite. ${ }^{23}$

\subsubsection{Small-Column Study with Zeolite}

A small-column test was performed in FY 1995 to verify the sorption capacity and the $K_{d}$ values of strontium and cesium on zeolite under dynamic flow conditions. Cation breakthrough from the column implied that the selectivity of the treated zeolite is as follows: $\mathrm{Cs}>\mathrm{Sr}>\mathrm{Ca}>\mathrm{Mg}>\mathrm{Na}$. The fractional breakthrough $\left(\mathrm{C} / \mathrm{C}_{0}\right)$ of the competing cations, defined as the ratio of the cation concentration in the column effluent to the concentration in the feed, stabilized at a value of 1.0 at approximately 800 to 1400 bed volumes (BVs).

The ${ }^{85} \mathrm{Sr}$ and ${ }^{137} \mathrm{Cs}$ count rates of the effluent fractions were compared with those of the feed solutions to determine breakthrough points. Strontium was first observed in the column effluent at approximately $3000 \mathrm{BVs} ; 50 \%$ breakthrough occurred at $15,000 \mathrm{BVs}$. Cesium breakthrough was $1 \%$ after about 15,000 BVs and $50 \%$ after about $50,000 \mathrm{BVs}$. The strontium loading for the zeolite was about $60 \mathrm{meq} / \mathrm{kg}$ at $50 \%$ breakthrough; the cesium loading was $0.2 \mathrm{meq} / \mathrm{kg}$ at $50 \%$ breakthrough. These loadings, particularly the strontium loading, were higher than the saturation loadings of about 24 and $0.17 \mathrm{meq} / \mathrm{kg}$ measured previously for strontium and cesium, respectively, in batch sorption isotherms. The breakthrough data were used to construct logarithmic-probability plots of strontium and cesium breakthrough vs column throughput. These 
plots were used to estimate column $\mathrm{K}_{\mathrm{d}}$ values, which are approximately equal to the number of bed volumes at $50 \%$ breakthrough. ${ }^{24}$ The $\mathrm{K}_{\mathrm{d}}$ values for the radionuclides, although slightly lower, were in good agreement with those predicted in batch sorption isotherms:

\begin{tabular}{lcc} 
& \multicolumn{2}{c}{$\mathrm{K}_{\mathrm{d}}(\mathrm{L} / \mathrm{kg})$} \\
\cline { 2 - 3 } Zeolite test & Strontium & Cesium \\
\hline Column & 15,800 & 53,000 \\
Batch isotherm & 17,000 & 80,000
\end{tabular}

\subsection{SORPTION CHARACTERISTICS OF R-F ION-EXCHANGE RESIN}

\subsubsection{R-F Resin Batch Tests}

Batch testing of the R-F resin in FY 1995 focused on the removal of strontium and cesium activity from the wastewater simulant. As observed with the chabazite zeolite, the cesium isotherm was essentially linear in the wastewater simulant. The cesium sorption capacity on the resin was $0.02 \mathrm{meq} / \mathrm{kg}$, as compared with $0.17 \mathrm{meq} / \mathrm{kg}$ on the sodium-modified zeolite. The cesium data fit the empirical Freundlich model [Eq. (7)] best. A linear relationship was obtained between the log milliequivalents per liter of the final concentration of cesium in solution and the log milliequivalents of cesium sorbed per kilogram on the resin. The slope of the line was equivalent to 0.92 , and the intercept was equivalent to 3.4 , with a correlation coefficient for the linear fit of 0.995 . Therefore, the equation governing cesium sorption on water-washed resin is as follows:

$$
K_{d}=2500 \times C^{-0.08}
$$

Strontium isotherms, developed by treating $10-\mathrm{mL}$ solutions with $5-100 \mathrm{mg}$ of water-washed R-F resin, had two inflection points (Fig. 6). In the absence of corresponding competing cation data, strontium sorption data were initially linearized using the empirical BET sorption model equation. A small-column test was conducted in early FY 1996 to verify the prediction of strontium column breakthrough, based on the BET equation. The estimate of strontium breakthrough was almost twice as large as that observed from an actual column experiment. Activities in the latter part of FY 1996 centered on determining the fate of competing cations in the wastewater simulant so that column breakthrough on R-F resin could be more accurately predicted. In addition to nuclide removal, the cation content of the final treated simulant was determined by 


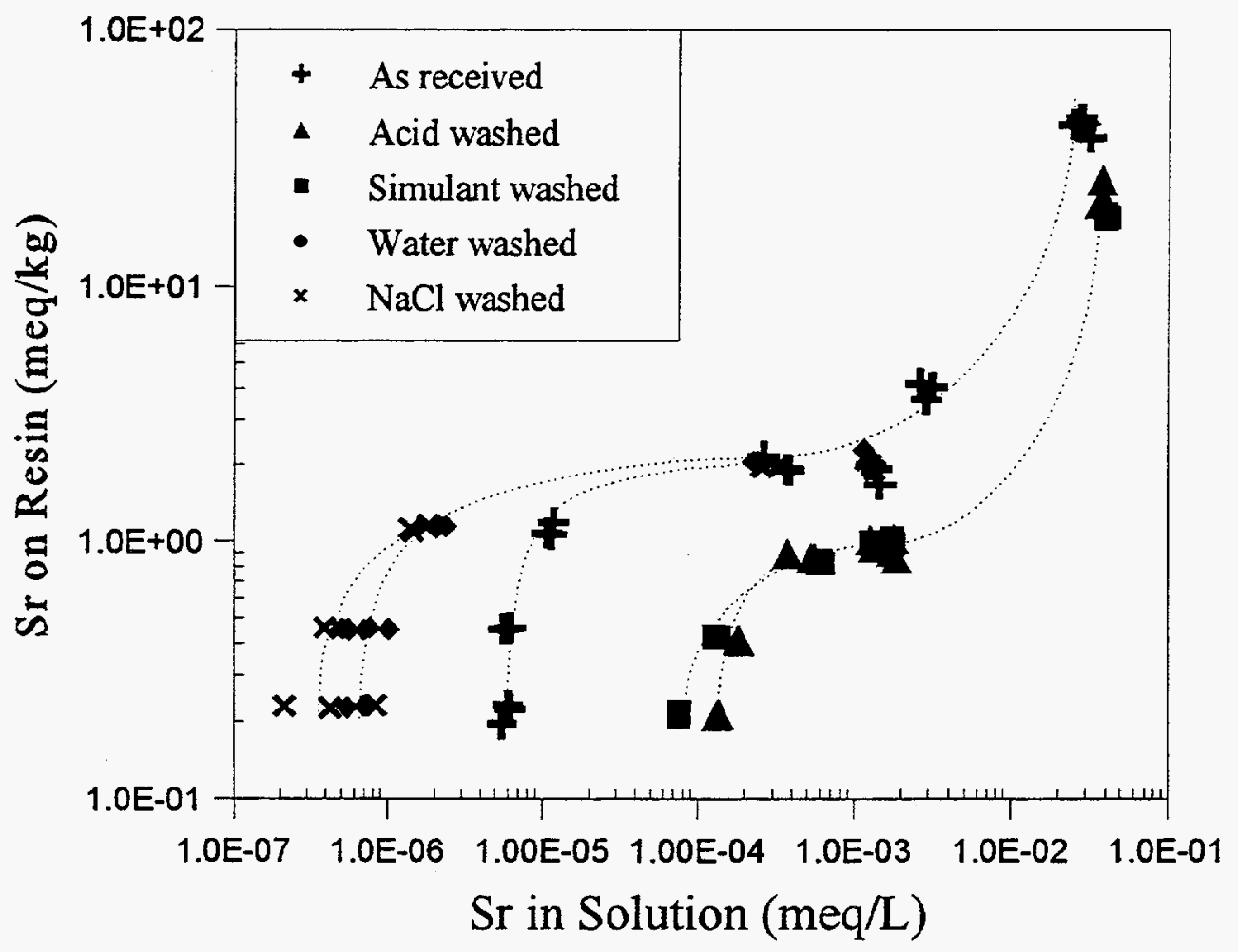

Fig. 6. Strontium sorption on pretreated R-F resin. Test conditions: 0.005 to $0.100 \mathrm{~g}$ of resin in $10 \mathrm{~mL}$ of process wastewater simulant; 24-h equilibration time; initial concentration of strontium for lower data points, $0.00228 \mathrm{meq} / \mathrm{L}$; initial concentrations of strontium for upper data point, $0.05 \mathrm{meq} / \mathrm{L}$. 
ICP analysis. It appears that the curvilinear strontium isotherm on $\mathrm{R}-\mathrm{F}$ resin is the result of the nonselective sorption of strontium, magnesium, and calcium from the wastewater simulant. Strontium sorption was observed in a series of samples in which the total metal(II) concentration was varied, as well as the $\mathrm{Mg} / \mathrm{Ca}$ ratio initially present in the simulant.

A Freundlich plot of the sorption results, presented in Fig. 7, indicates that the sorption of total metal(II), that is, $\mathrm{Ca}+\mathrm{Mg}+\mathrm{Sr}$, in solution is linear with the total metal sorbed onto the resin. The quantity of the individual divalent ions sorbed onto the resin (in units of milliequivalents per kilogram) can be calculated as the equivalent ionic fraction of that ion relative to the total equivalents of alkaline earth metals present in the solution at equilibrium:

$$
\text { Sr on exchanger }=\mathrm{Sr} \text { equiv. fraction } \times 2410 \times\left[\text { total metal(II) }{ }_{\text {iq }}\right]^{(0.22)} \text {. }
$$

The strontium $\mathrm{K}_{\mathrm{d}}$ can then be determined by dividing the calculated quantity sorbed on the exchanger by the concentration of strontium, in units of milliequivalents per liter, at equilibrium. The resulting calculation reduces to

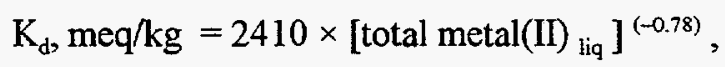

where the concentration of total metal(II) is given in units of milliequivalents per liter.

Equation (14) demonstrates the dependency of strontium sorption on the concentration of total alkaline earth metals in wastewater. The concentrations of $\mathrm{Sr}, \mathrm{Mg}$, and $\mathrm{Ca}$ in the waste simulant are $3.11 \times 10^{-3}$, 0.54 , and $1.87 \mathrm{meq} / \mathrm{L}$, respectively. Therefore, $\mathrm{Mg}$ and $\mathrm{Ca}$ concentrations are the primary parameters defining the magnitude of the Sr $\mathrm{K}_{d}$ in wastewater. By using Eq. (13), the $\mathrm{K}_{d}$ for strontium in the simulant was calculated to be $1200 \mathrm{~L} / \mathrm{kg}$. The strontium sorption capacity for column feed having the above composition is, therefore, $3.6 \mathrm{meq} / \mathrm{kg}$ on the resin.

In light of Eq. (14), the curved profiles for strontium sorption presented in Fig. 6 are the result of removing strontium from solutions containing varying concentrations of total metal(II) cations. Nonselectivivity between the alkaline earth metals also explains the sorptive characteristics of the various pretreated resin batches. Pretreating the resin with either water or saline partially hydrolyzes the resin or converts the resin to the sodium form, respectively. Both of these resin forms enhance the nonselective removal of metal(II) cations. The sorption isotherm is linearized by pretreating the resin with simulant, 


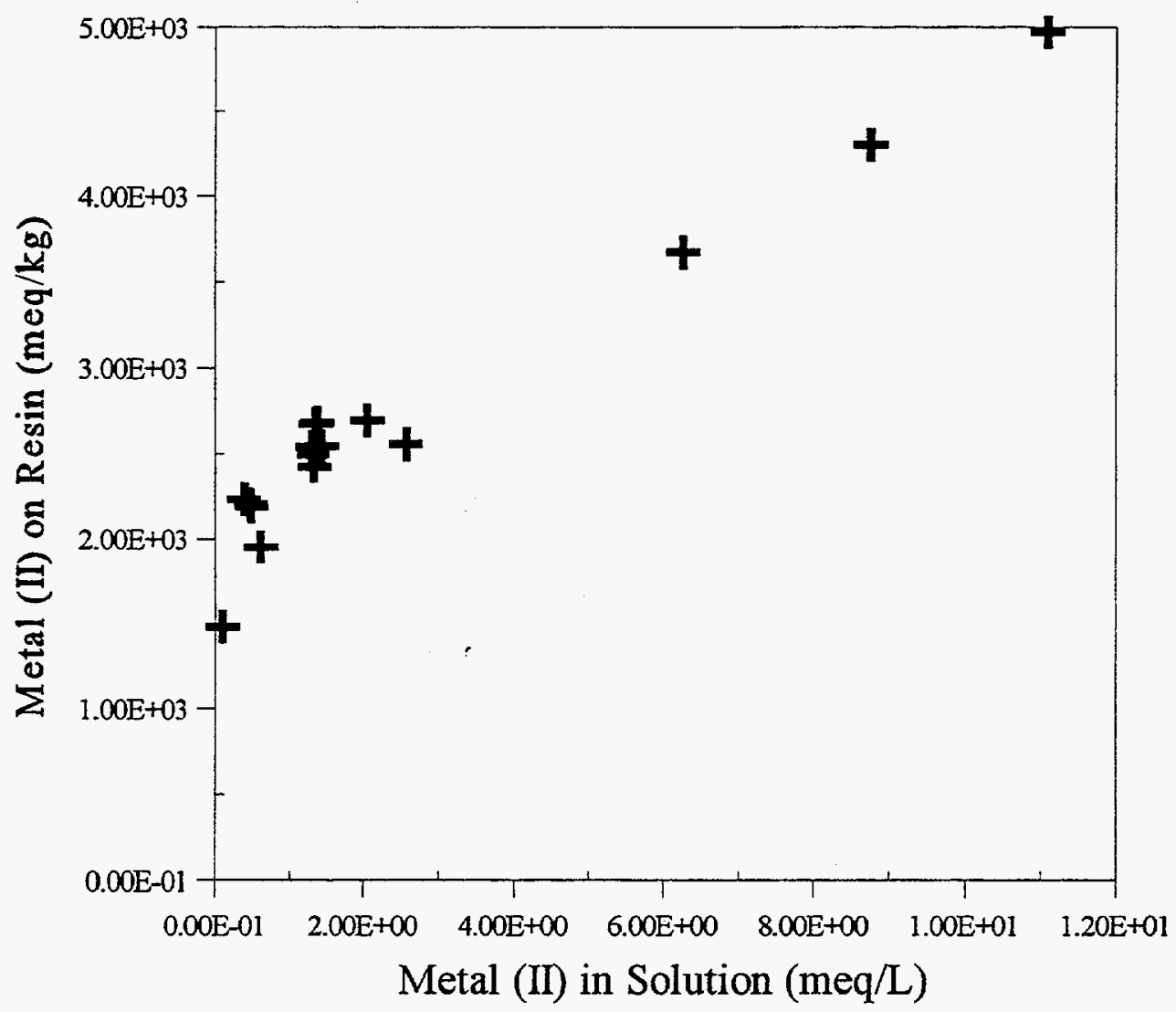

Fig. 7. Metal (II) sorption data on water-washed R-F resin. Test conditions: $0.010-0.200 \mathrm{~g}$ R-F resin in $20 \mathrm{~mL}$ of process wastewater simulant; 24-h equilibration time; initial $\mathrm{Sr}$ simulant concentration, $0.00228 \mathrm{meq} / \mathrm{L}$; initial total metal (II) concentration, $0.5-11.1 \mathrm{meq} / \mathrm{L}$. 
which preloads the resin with $\mathrm{Mg}$ and $\mathrm{Ca}$. Additionally, conversion of the resin to the hydrogen form with $\mathrm{HCl}$ linearizes the isotherm by minimizing further $\mathrm{Mg}$ and $\mathrm{Ca}$ (and, thus, $\mathrm{Sr}$ ) sorption from the simulant.

\subsubsection{Small-Column Test with R-F Resin}

The lack of selectivity among alkaline earth cations is further demonstrated in the breakthrough profile (Fig. 8) obtained from a small-column test run under conditions similar to those used previously for zeolite characterization. The dry-packed density of the resin column was $0.43 \mathrm{~g} / \mathrm{mL}$, as compared with $0.55 \mathrm{~g} / \mathrm{mL}$ for the zeolite column test. The feed solution in each column test contained 0.0023 meq $/ \mathrm{L}$ total strontium and $2.4 \times^{-6} \mathrm{meq} / \mathrm{L}$ total cesium. The average flow rate of the feed through the resin column was $1.23 \mathrm{~mL} / \mathrm{min}$ at a column cross-sectional area of $0.079 \mathrm{~cm}^{2}$. Sodium and potassium cations were eluted from the resin column immediately. Alkaline earth cations, including strontium, were eluted simultaneously after 400 BVs of simulant had been treated. Fifty percent breakthrough for strontium and cesium occurred at 525 and $6400 \mathrm{BVs}$, respectively. Desorption of the radionuclides from the R-F resin column was observed beyond the $100 \%$ breakthrough points, as indicated by the concentration spikes that were greater than feed concentrations of both strontium and cesium.

Once the cesium concentration in the eluent returned to that of the feed solution, the run was terminated. At this point, the strontium and cesium remaining on the resin were eluted with $0.5 \mathrm{MHCl}$. Fifteen fractions, collected in 1-BV aliquots, were eluted from the column. Ninety-nine percent of the total amount of desorbed strontium and cesium was eluted within the first 6 and $13 \mathrm{BVs}$ of acid, respectively. The strontium concentration in the column fraction representing the 15 th $\mathrm{BV}$ was $4 \%$ of the original column feed concentration. However, after the 15 th $\mathrm{BV}$, the cesium concentration in the eluate was still 10 times greater than in the wastewater simulant. The cumulative activity of the acidic fractions indicates that approximately 9 meq strontium and $5 \times 10^{-5}$ meq cesium were stripped from the column. During the stripping process, the bed height of the resin decreased by $14 \%$ in the presence of $0.5 \mathrm{MHCl}$. Further loading and stripping cycles were not performed with this column.

Fifty-percent column breakthrough data were used to estimate the column $K_{d} s$, tabulated as follows, for strontium and cesium sorption on R-F resin: 


\begin{tabular}{lcc} 
& \multicolumn{2}{c}{$\mathrm{K}_{\mathrm{d}}(\mathrm{L} / \mathrm{kg})$} \\
\cline { 2 - 3 } R-F test & Strontium & Cesium \\
\hline Column & 1,260 & 15,400 \\
Batch isotherm & 1,200 & 14,500
\end{tabular}

The close comparison of batch test predictions and colums- performance indicates that a Freundlich sorption model can be used to adequately predict strontium and cesium column breakthrough on washed R-F resin with this particular wastewater composition.

\subsubsection{Calculations of Mass Transfer Parameters for R-F Resin}

A more rigorous evaluation of the R-F column breakthrough data was performed using a method developed by Doulah and $\mathrm{Jafar}^{25}$ for the prediction of mass transfer parameters. This particular method describes breakthrough curves as a function of the probability of mass transfer in the sorption zone. The probability function is fit to three variables that describe the slope, time of appearance, and mean time of the breakthrough curve. As such, Doulah's calculations are free of a priori assumptions of mass transfer mechanisms. Doulah's probability function, used to describe the breakthrough profile, takes the form of a Weilbull-type probability function

$$
p=\left(\beta / \theta_{m}\right)\left[\left(\theta-\theta_{0}\right) / \theta_{m}\right]^{\beta-1}
$$

where $\beta$ describes the shape of the curve, $\theta_{0}$ represents the time of $5 \%$ nuclide breakthrough, $\theta_{\mathrm{m}}$ signifies the mean time of the breakthrough curve, and $\theta$ is the time of a particular data point within the breakthrough region. Because

$$
\frac{\mathrm{d}\left(\mathrm{C} / \mathrm{C}_{0}\right)}{\mathrm{C} / \mathrm{C}_{0}}=-\mathrm{pd} \theta
$$

integration of Eq. (15), after substitution of the variable p from Eq. (16), yields

$$
\mathrm{C} / \mathrm{C}_{0}=\exp \left\{-\left[\left(\theta-\theta_{0}\right) / \theta_{\mathrm{m}}\right]\right\}^{\beta}
$$




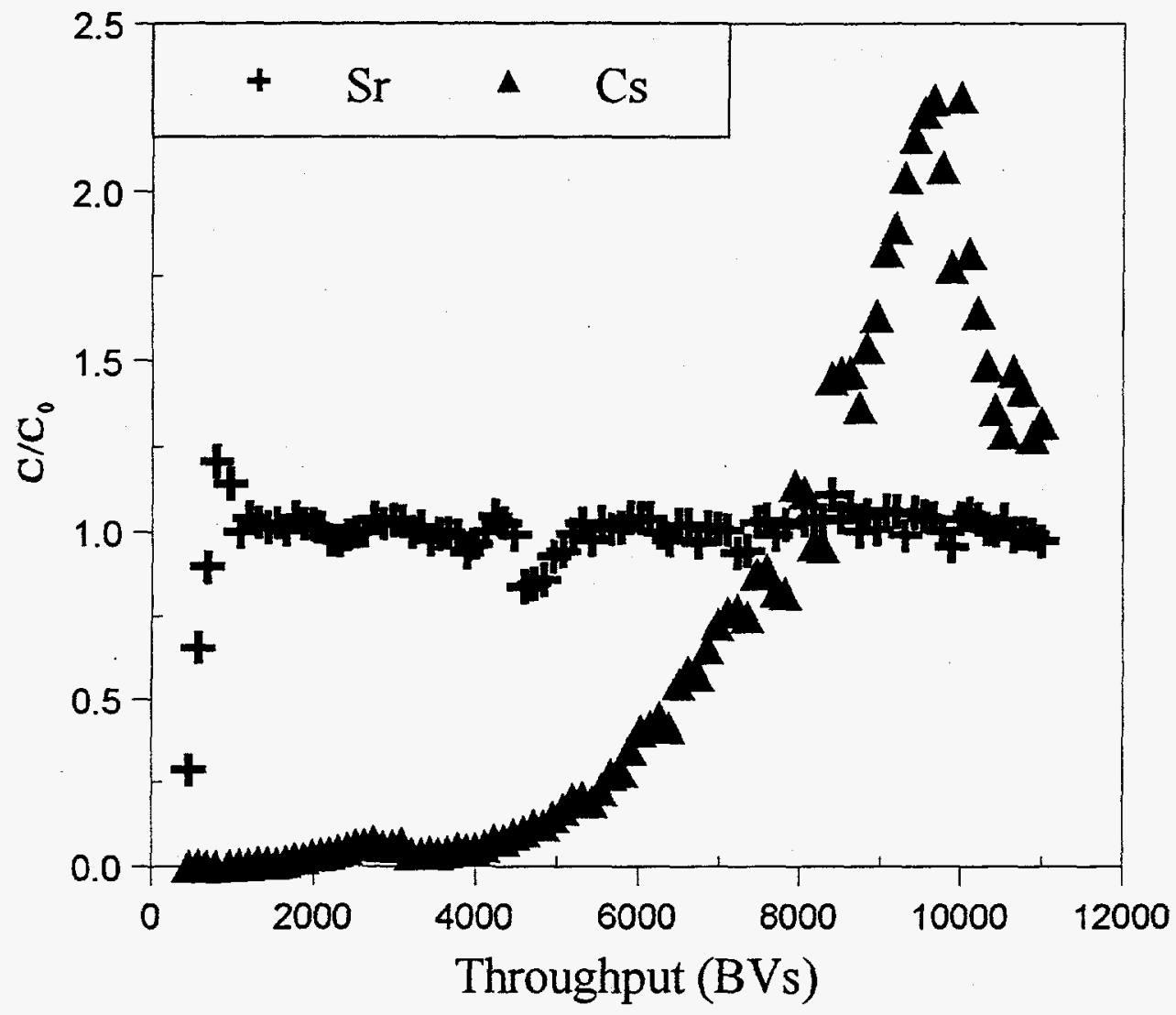

Fig. 8. Breakthrough curves of strontium and cesium on water-washed $\mathrm{R}-\mathrm{F}$ resin. Column parameters: $1.4 \mathrm{~g}$ (dry weight) waterwashed resin contained in 1-cm-diam column having a bed volume of $3.85 \mathrm{~mL}$. Process wastewater simulant flow rate was $1.23 \mathrm{~mL} / \mathrm{min}$. 
Equation (17) describes the breakthrough curve within the breakthrough zone; the mirror image of the curve represents data outside the breakthrough zone, or

$$
C / C_{0}=1-\exp \left\{-\left[\left(\theta-\theta_{0}\right) / \theta_{m}\right]^{\beta}\right\}
$$

The parameters in the above equations can be quantified by plotting $\log \ln \left(\mathrm{C} / \mathrm{C}_{0}\right)$ for $\mathrm{C} / \mathrm{C}_{0}$ values over the range of $0.05-0.95$ against $\log \left(\theta-\theta_{0}\right)$. The time, $\theta$, is corrected for the amount of time required to elute the column void volume, or

$$
\theta=\mathrm{t}-\mathrm{eH} / \mathrm{U}_{\mathrm{s}},
$$

where $t$ is the time during breakthrough, $e$ is the column void fraction, $H$ is the column bed height, and $U_{s}$ is the superficial velocity of the column feed. The term $\theta_{m}$ represents the point at which $C / C_{0}=0.632$, that is, where $\ln \left(C / C_{0}\right)=1$. The slope of the plot is equivalent to $\beta$, and the intercept is equal to $-\beta \log \theta_{m}$.

Table 15 summarizes the operating conditions and calculated parameters for the R-F column study. (Similar information for the zeolite column test is presented in Table 16 for comparison.) Since the distribution coefficient is calculated at a breakthrough point of $\mathrm{C} / \mathrm{C}_{0}=0.632$, its value is somewhat higher than the values listed within the text of this report, which are based on $50 \%$ breakthrough data. The column distribution ratio (D) incorporates the volume of the resin, void volume, and interstitial column volume into the calculation. ${ }^{9}$

\subsection{SORPTION CHARACTERISTICS OF SODIUM NONATITANATE}

Batch testing of sodium nonatitanate samples was initiated in FY 1996. Two forms of the sorbent were received from AlliedSignal Research and Technology: (1) a fine powder having an average particle size of $25 \mu \mathrm{m}$, and (2) 1-mm-diam by 3 -mm-long pellets, each weighing approximately $20 \mathrm{mg}$. Additional physical characteristics of these materials are given in Table 2.

Batch sorption isotherms of the nonatitanate powder resemble those acquired using the R-F resin (Fig. 9). The curvilinear profile implies sorption of other cations, in addition to strontium, from the wastewater simulant. The final concentrations of $\mathrm{Na}, \mathrm{K}, \mathrm{Ca}$, and $\mathrm{Mg}$ in batch samples treated with varying amounts of nonatitanate powder were analyzed by the ICP technique to confirm multiple cation sorption. After a 22-h equilibration, the sodium-ion concentration increased by a factor of 20 when as much as $100 \mathrm{mg}$ of the as-received nonatitanate was added to $10 \mathrm{~mL}$ of simulant. The potassium concentration decreased by 
Table 16. Conditions and parameters for zeolite column study

Column operating conditions

Bed volume, $\mathrm{mL}$ 3.8

Bed height, $\mathrm{cm}$

4.9

Dry zeolite weight, $g$

1.9

Superficial velocity, $\mathrm{cm} / \mathrm{h}$

94

Calculated column parameters

Strontium

Cesium

Distribution coef., $\mathrm{L} / \mathrm{kg}$

42,000

130,000

Column distrib. coef., L/L

8,600

26,000

Saturation capacity, meq/g

$9.7 \times 10^{-2}$

$3.3 \times 10^{-4}$

Degree of bed saturation, $\%$

26

39

Liq. mass transfer coef., $K_{1} a, 1 / h$

0.011

0.00055

No. theoretical mass transfer plates

1.3

1.6

Height of theoretical plate, $\mathrm{cm}$

3.6

3.0 


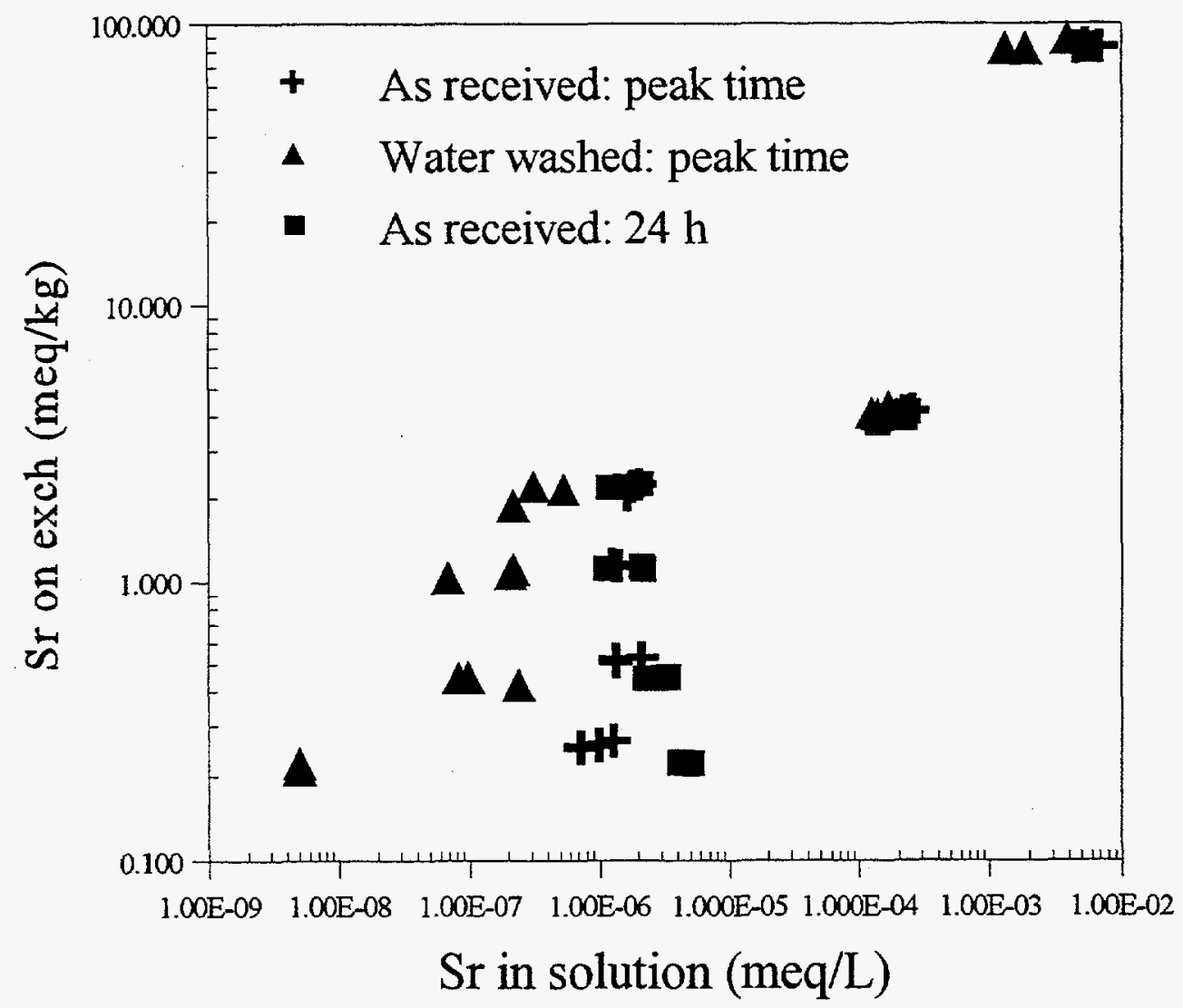

Fig. 9. Strontium sorption on sodium nonatitanate powder. Test conditions: $0.005-0.100$ g sodium nonatitanate powder in $10 \mathrm{~mL}$ of wastewater simulant; 24 -h equilibration time; initial simulant concentration for lower data points, $0.00228 \mathrm{meq} / \mathrm{L} \mathrm{Sr}$; initial simulant concentrations for upper data points, $0.05 \mathrm{meq} / \mathrm{L} \mathrm{Sr}$ and $0.04 \mathrm{meq} / \mathrm{L} \mathrm{Cs}$. 
$40 \%$. When 10-100 $\mathrm{mg}$ of the nonatitanate powder was added to the simulant, both magnesium and calcium were completely removed from solution. These results suggest that, concurrent with the release of sodium ion, significant quantities of calcium and magnesium were sorbed from the 10-mL simulant during a batch test with as-received nonatitanate.

The notable difference between sorption on R-F resin and sorption on nonatitanate is that the latter is both concentration and time dependent. Figure 9 illustrates sorption data for various sorbent loadings, collected at a constant mixing time. Two additional series of data, taken at the time of maximum strontium sorption for each sorbent loading, are also plotted in Fig. 9. The difference in the shape of the latter two isotherms reflects the differences in the extent of strontium sorption at various contact times. To better understand this phenomenon, cation sorption on the nonatitanate powder was studied both as a function of time and as a function of cation concentration in the simulant. Four sets of samples were prepared, having initial cation compositions for each "head" solution, or head, as listed in column 1 of Table 17. Note that the initial composition of each of these solutions was intentionally greater than that of the typical wastewater simulant (Table 1) so that strontium sorption could be observed in a treated sample having a final concentration resembling that of the PWTP simulant. Additional calcium and magnesium, in a ratio identical to that present in head 1 , were added to elevate the total metal content in the remaining three head solutions. In the head 4 solution, strontium was added at a level four times that of the first three heads. The goal of this set of experiments was to follow cation sorption prior to and following the point of maximum strontium sorption so that the defining mechanism controlling this process could be determined.

To date, time-dependence data have been collected for sorbent contact times of $0.25-48 \mathrm{~h}$. This time frame is sufficient to observe maximum strontium sorption from $10 \mathrm{~mL}$ of sample solution treated with $5 \mathrm{mg}$ of nonatitanate powder. Test results for any given simulant composition show that the selectivity among $\mathrm{Sr}$, $\mathrm{Mg}$, and $\mathrm{Ca}$ is approximately equivalent within the first few minutes of sorbent contact (Fig 10). With increasing contact times, the $\mathrm{Mg}$ sorption ratio remains constant while $\mathrm{Sr}$ and $\mathrm{Ca}$ sorption ratios increase. Therefore, the selectivity for $\mathrm{Sr}$ and $\mathrm{Ca}$ over $\mathrm{Mg}$ increases with time. Maximum sorption for calcium and strontium is reached at 16 and $23 \mathrm{~h}$, respectively.

Table 17 also lists the solution composition of each treated head sample at the peak time for strontium sorption. The final composition of head 1 at $23 \mathrm{~h}$ represents the calcium and magnesium concentrations of process wastewater. Thus, the strontium sorption ratio of $890 \mathrm{~L} / \mathrm{kg}$ reflects that which will probably be observed in this type of wastewater at a treatment ratio of $5 \mathrm{mg}$ to $10 \mathrm{~mL}$ of sample. This value is approximately equivalent to that observed for R-F resin in a process wastewater simulant and is a factor of 10 less than that obtained for the chabazite zeolite under similar conditions. The final composition of head 3 
Table 17. Effect of increased alkaline earth metal content on rate of cation sorption

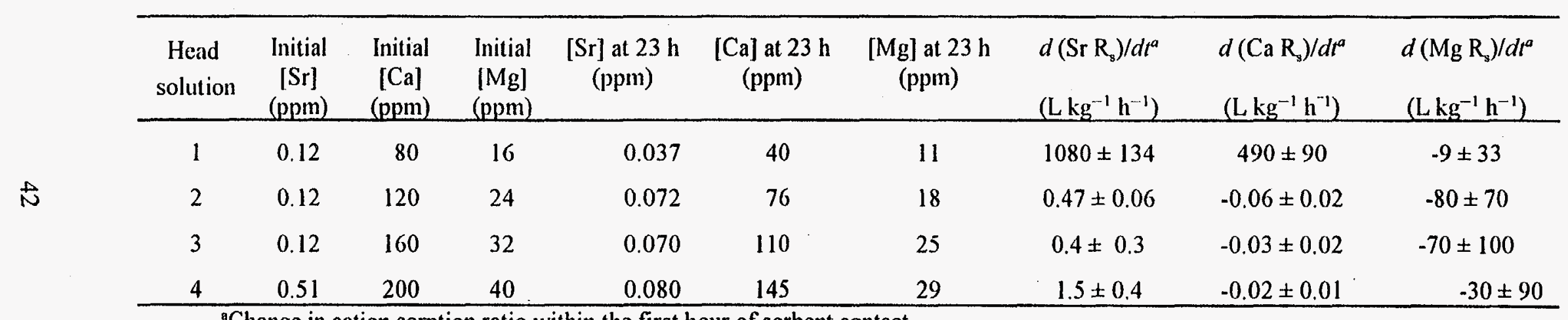

${ }^{a} \mathrm{C}$ hange in cation sorption ratio within the first hour of sorbent contact. 
at $23 \mathrm{~h}$ is similar to that of groundwater; the sorption ratios for $\mathrm{Sr}, \mathrm{Ca}$, and $\mathrm{Mg}$ from this concentrated sample were calculated to be 1000,400 , and $170 \mathrm{~L} / \mathrm{kg}$, respectively.

An attempt was made to determine the order of the strontium rate reaction from data presented in Fig. 10. The aqueous strontium concentrations remaining in solution after contact times of $0.25-1 \mathrm{~h}$ were plotted against time. A linear relationship between the strontium concentration, the log of strontium concentration, or the inverse of strontium concentration with time should indicate whether the reaction rate was zero, first, or second order with time. Linear regression analysis of each plot indicated that the correlation coefficient between the strontium concentration variable and time was 0.92 in each case. Therefore, no definitive judgment could be made with regard to the reaction order from these experimental data.

In comparing the cation sorption data of the various starting solutions, the time of maximum sorption for either calcium or strontium was observed to be independent of the initial solution composition. However, the amount of cation sorption at maximum time was significantly affected by the total metal composition of the wastewater. Figure 11 illustrates the decrease in the strontium sorption rate as the total divalent cation content of head samples became more concentrated. Calcium sorption was similarly affected. The magnesium sorption ratios in heads 2-4 were equivalent and were only $30 \%$ of that observed in head 1 . Table 17 summarizes the depression of the sorption ratio as a function of the contact time for each head solution. The coefficient of variation presented in the table reflects the variance in duplicate series of samples. The scatter in the magnesium data confirms the fact that the sorption ratio for this particular cation is independent of time or total metal concentration. However, the decreases in calcium and strontium sorption rates are significantly greater than the observed variance within data sets. Additionally, the strontium and calcium sorption ratios are independent of time as the ionic strengths of the metal concentrations in the treated solutions approach that of groundwater composition.

The relative decrease in the strontium sorption ratio appears to be similar to that for calcium. Although the $\mathrm{Sr}$ sorption ratio is greater at any given time, both $\mathrm{Ca}$ and $\mathrm{Sr}$ sorption rates decrease to the same extent as a function of total metal concentration (Fig. 11). Additionally, although the initial strontium concentration in head 4 is four times greater than the concentrations in the first three heads, the sorption data from this solution fall in line with those of the first three samples. This agreement suggests that it is the total metal concentration (or possibly $\mathrm{Ca}$ or $\mathrm{Mg}$ individually, since the ratio of these two components was kept constant in the head solutions tested) that controls the amount and rate at which $\mathrm{Sr}$ sorbs onto the nonatitanate powder. The initial amount of $\mathrm{Sr}$ in the waste matrix appears to have little influence on the $\mathrm{Sr}$ sorption ratio and the rate of $\mathrm{Sr}$ sorption onto the nonatitanate. This characteristic is very similar to Sr sorption on the R-F resin. 


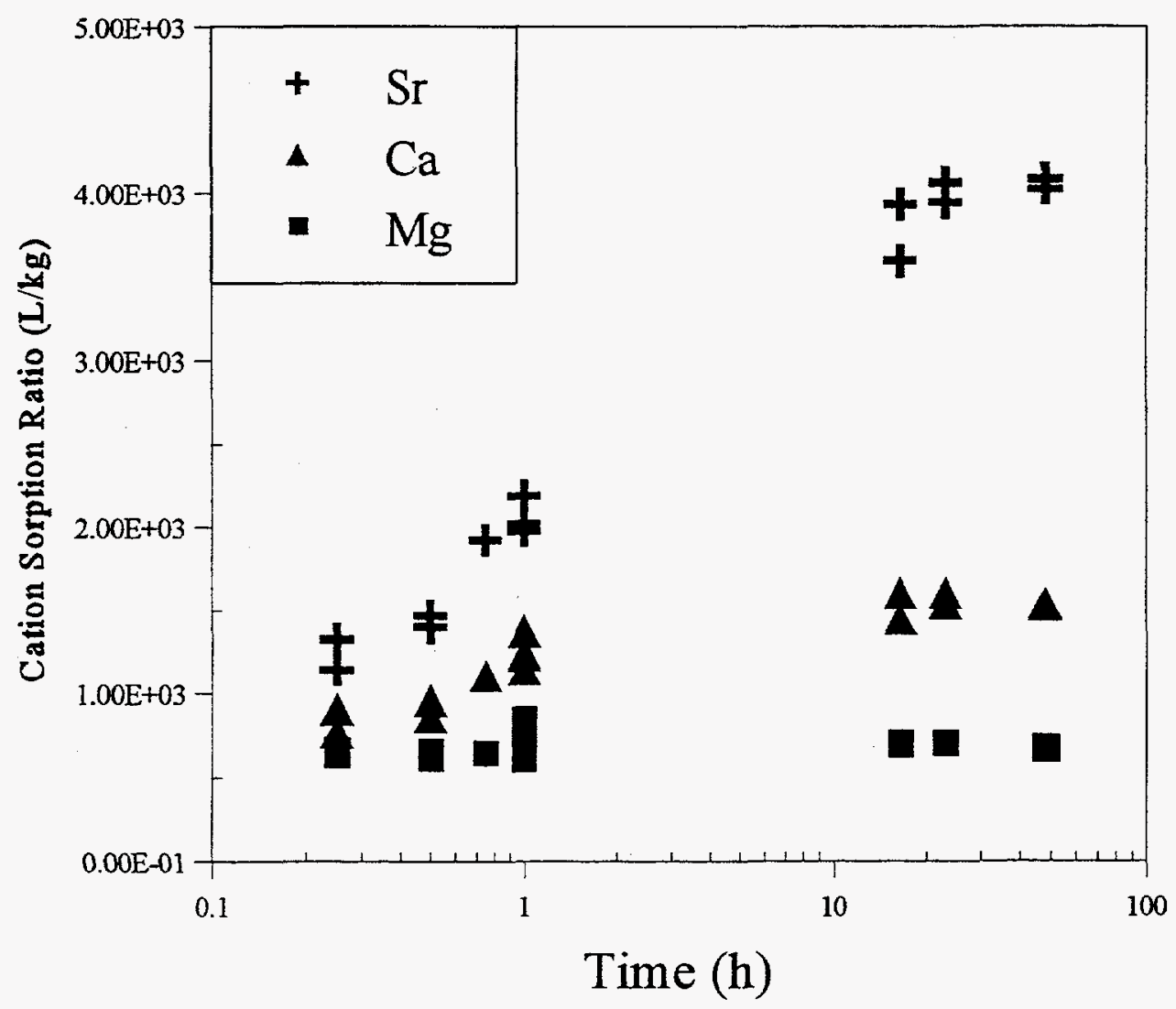

Fig. 10. Change in cation sorption ratios as a function of sorbent contact time. Test conditions: $0.01 \mathrm{~g}$ as-received nonatitanate powder in $20 \mathrm{~mL}$ of head 1 simulant; initial concentrations, $0.00228 \mathrm{meq} / \mathrm{L}$

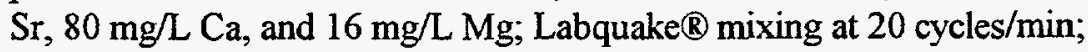
samples centrifuged at $5000 \mathrm{rcf}$ for $30 \mathrm{~min}$ and filtered through a $0.1-\mu \mathrm{m}$-pore Supor Acrodisc polysulfone membrane. 


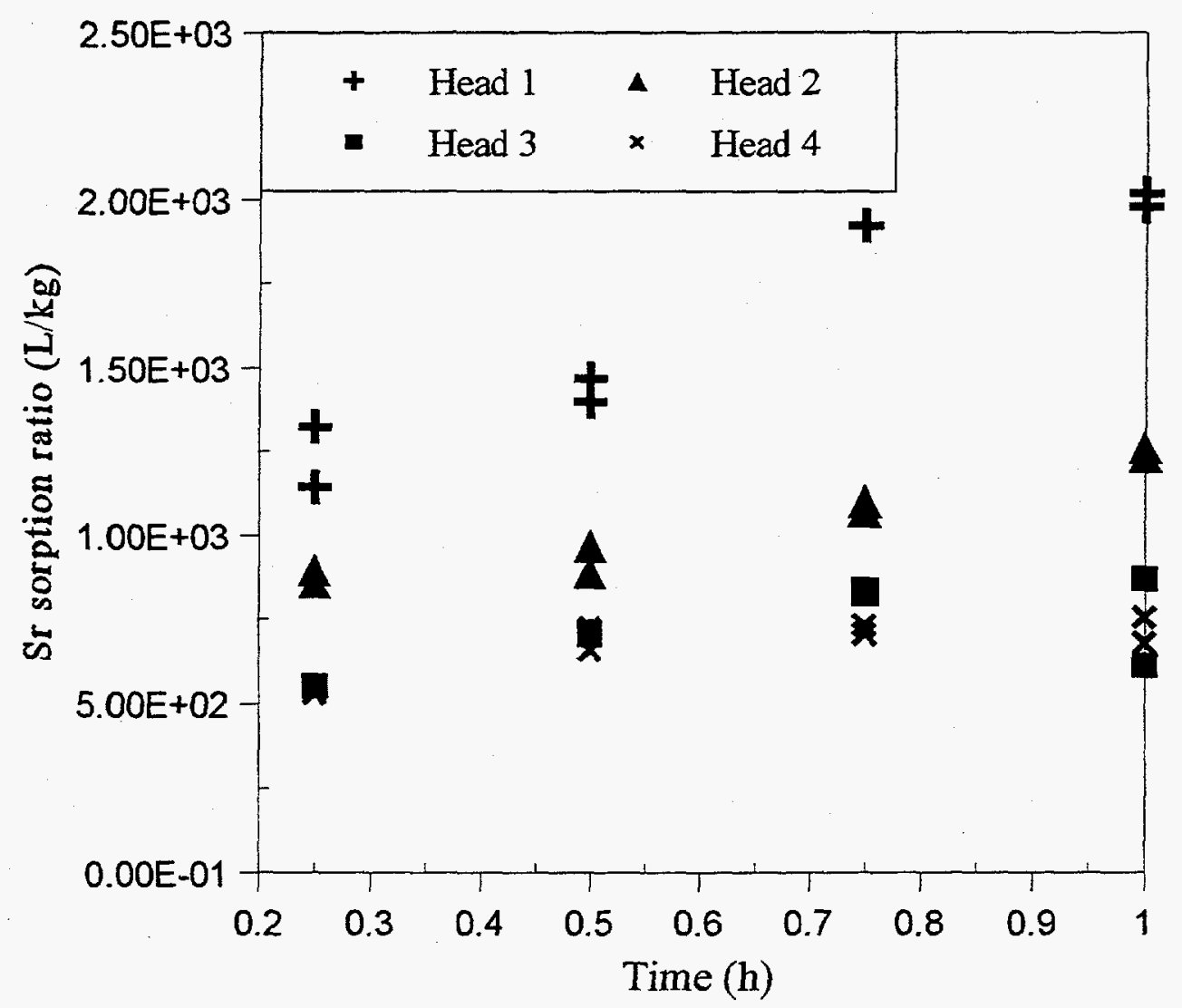

Fig. 11. Effect of initial metal content on the rate of strontium uptake on nonatitanate powder. Test conditions: $0.01 \mathrm{~g}$ as-received nonatitanate powder in $20 \mathrm{~mL}$ of simulant; Labquake $B$ mixing at 20 cycles/min; samples centrifuged at $5000 \mathrm{rcf}$ for $30 \mathrm{~min}$ and filtered through a $0.1-\mu \mathrm{m}$-pore Supor Acrodisc polysulfone membrane. 
Because of the poor selectivity among alkaline earth metals, the Sr sorption ratio on either R-F resin or nonatitanate is determined primarily by the significantly greater amounts of $\mathrm{Ca}$ and $\mathrm{Mg}$ in wastewater.

Several additional experiments must be performed before strontium sorption on nonatitanate can be fully understood. The calcium and magnesium concentrations need to be varied independently in solution to determine whether one or both of these cations could be responsible for depressing the Sr sorption rate in the 0.25- to 48-h time frame. In addition, batch studies are still needed to determine why strontium desorbs from the powder after extended mixing times (48-200 h) as suggested by the data plotted in Fig. 3. A complete understanding of the kinetics of sorption will be necessary to successfully take advantage of strontium sorption on nonatitanate in column applications.

\subsection{SORPTION CHARACTERISTICS OF POTASSIUM IRON(II) HEXACYANOFERRATE}

A sample of a commercial sorbent produced by the Russian-Canadian JV firm "Compomet Cantec" was received through F. Seamon, of Seatek International, for preliminary evaluation. This material, called FEZHEL (or ANFEZH), is a sorbent comprised of wood fiber cellulose coated with potassium iron ferrocyanide. A U.S. patent (No. 5,407,889) for the method of manufacturing the material was granted to V. P. Remes in April 1995. FEZHEL, which is currently being produced at pilot scale (100 tons per year) in Yekaterinburg, Russia, was developed for selectively sorbing $\mathrm{Cs}, \mathrm{Co}$, and $\mathrm{Mn}$ from dilute aqueous solutions. It has been used successfully in the treatment of municipal wastewater, freshwater, and marine water and as a dairy feed additive in the former Soviet Union and elsewhere in Europe.

Two containers of sorbent were received in our laboratory. One bag, labeled ANFEZH, contained a dark-blue fibrous material in which $75 \%$ of the dry sorbent particles were in the -20 to +50 U.S. sieve range $(0.3-0.8 \mathrm{~mm})$; and $23 \%$ of the particles were less than $0.3 \mathrm{~mm}$. (ANFEZH sorbents present a problem in sizing. Particle sizing by sieve analysis is most accurate with spherical particles that are not dependent on their orientation during passage through the sieve screens. The size analysis of ANFEZH sorbent is influenced by the fact that many of the sorbent particles are long, thin fibers. These fibers may slip, when in the "end-on" orientation, through the screen and artificially lower the determination of average particle size.) The second, unlabeled, lot of sorbent contained a mixture of light-blue and dark-blue fibers; again, most of the dry fibers were within the -20 to +50 sieve range. The variation in color between the two lots of sorbent was assumed to reflect a difference in the iron(II)/iron(III) ratio of the iron hexacyanoferrate. The light-blue color might be an indication of the presence of potassium iron(II) ferrocyanide, while the more deeply colored material might contain a higher percentage of iron(III) ferrocyanide. 
The time to reach maximum sorption on ANFEZH was determined by mixing $0.020 \mathrm{~g}$ of as-received sorbent with $10 \mathrm{~mL}$ of wastewater simulant and placing the samples on a Labquake mixer for a period ranging from $2 \mathrm{~h}$ to 13 days. Each sample was then centrifuged to clarify the solution before the final radionuclide activity was determined. Because accompanying literature suggested the possibility of $\mathrm{Sr}$ decontamination, the equilibrium times for both $\mathrm{Cs}$ and $\mathrm{Sr}$ were observed. Results indicate that only $20 \%$ of the strontium was removed from the treated samples; strontium decontamination was found to be independent over this time frame. Maximum cesium removal occurred within a 48-h mixing period. The decontamination factor, or DF (ratio of final cesium activity remaining in the treated solution as compared with the initial cesium activity), remained relatively constant for mixing times up to $250 \mathrm{~h}$. A small percentage loss in cesium removal was noted for longer contact times. The average cesium DF for mixing times of $48 \mathrm{~h}$ or greater was $830 \pm 240$ for the $20-\mathrm{mg}$ sorbent samples. (This equilibration time is twice that required for both the natural chabazite zeolite and the R-F resin previously tested as part of this program.) The relatively large standard deviation observed in the cesium DF can be accounted for by the affinity of some of the cellulose fibers for the surface of the polypropylene mixing tube, the presence of long fibers in some of the samples, and the tendency of these long fibers to float on the solution surface.

A sorption isotherm profile was developed by mixing $5-100 \mathrm{mg}$ of as-received ANFEZH in $10 \mathrm{~mL}$ of wastewater simulant for $48 \mathrm{~h}$. At the completion of the equilibration time, the samples were centrifuged and the supernate was filtered through a $0.1-\mu \mathrm{m}$ filter membrane. The highest DF was 1200 , obtained when 10 $\mathrm{mg}$ of ANFEZH was added to $10 \mathrm{~mL}$ of wastewater simulant. (This compares with cesium DFs under similar conditions for the following sorbents: sodium-modified zeolite-80; water-washed R-F resin-30.) When either less or more ANFEZH sorbent was added to $10 \mathrm{~mL}$ of simulant, the cesium decontamination was lower. Additionally, the treated simulant became discolored when more than $5 \mathrm{mg}$ of ANFEZH was used to remove cesium from 10-mL samples. A light-yellow color was observed if 10-20 mg of sorbent was used, probably indicating the presence of potassium ferrocyanide. A blue coloration assumed to be free potassium iron ferrocyanice was observed above $20 \mathrm{mg}$ of sorbent. The colored solutions were then refiltered using a $0.02-\mu \mathrm{m}$-pore filter membrane. The cesium DF was improved by a factor of 2 when the additional suspended solids were removed.

Isotherm results indicate that a significant amount of product reagents is present in the as-received ANFEZH sorbent. These reagents react with cesium in solution and interfere with cesium sorption on the ANFEZH particles. Product literature characterizing column applications using ANFEZH describe a water prewash step to remove excess reagents prior to cesium sorption. Evidently, batch applications will require 
pretreatment of ANFEZH prior to use. Therefore, a prewashed form of the sorbent is being shipped from the supplier for further batch testing.

\section{SCALEUP ISSUES PERTINENT TO THE IMPLEMENTATION OF TASK SORBENTS}

\subsection{BASELINE CHABAZITE ZEOLITE}

The comparison of natural chabazite zeolite with $\mathrm{R}-\mathrm{F}$ resin and nonatitanate demonstrated that, in this particular waste matrix, the sodium form of the zeolite had a greater sorption capacity for both strontium and cesium. Additionally, the preconditioned zeolite showed a greater selectivity for both of these radionuclides over competing cations common in process wastewater. This was particularly evident in the case of strontium, for which the waterwashed R-F resin demonstrated no distinct selectivity over the other alkaline earth metals tested. There are some operational considerations, however, in selecting natural zeolite for fixed-bed column processing of contaminated water. These include the fact that the natural zeolite is friable; fines are created in the transportation to and charging of a column. The zeolite has a significant heat of hydration; consequently, steam is initially generated when water is added to a column of fresh, dry zeolite and may produce voids in the column packing. With continued column use, fine zeolite particles and algae cement the column packing so that spent zeolite cannot be easily sluiced from the column. ${ }^{26}$ If it is considered to be a cost-effective measure, the natural zeolite can be charged with concentrated saline to displace the natural strontium already on the sorbent. (The natural strontium content, of course, will depend on the source of the natural zeolite.) Care must be taken to remove any excess sodium entrained in the column packing by this pretreatment process, so that it will not affect column performance. If this process is conducted properly, the lifetime of the column will be enhanced by $30 \%$. Some of the positive operational features of this particular sorbent are that the inorganic material does not swell significantly when wetted and the particle size does not change with compositional fluctuations in the waste matrix. The material is relatively dense; consequently, the column packing is not easily disturbed with changes in column operating pressures. Finally, waste immobilization procedures using grout/cement have already been defined for the final disposal of spent zeolite.

\subsection{SORPTION ON R-F RESIN}

Strontium sorption behavior on R-F resin is driven by overall metal(II) concentration. Because there is little selectivity for strontium over other alkaline earth metals, the resin loading capacity will be much lower than that of zeolite. Consequently, the saturation capacity will also be strongly dependent on fluctuations in wastewater composition. Placing a water-softening procedure upstream from the R-F resin column would 
probably extend the lifetime of the sorbent. However, such a procedure would further complicate the operational complexity and add to the inventory of secondary waste generated by the treatment flow sheet. Another attribute of this particular sorbent is that $60 \%$ of the purchased resin had a particle size greater than 80 mesh, although the specified manufacturing range is +35 to -50 . When the relative cost of the resin over the zeolite is considered, this is a sizable fraction to fall outside specifications. The as-received product contained a significant excess $(0.6 \mathrm{meq} / \mathrm{g})$ of potassium. Because the molal equilibrium constant suggests that potassium would be selected over cesium, the excess potassium will adversely impact cesium sorption from process water and may even impact potassium discharge limits if a large resin column is used. In addition to potassium, a large amount of organic leachables elutes from the resin bed initially. The $\mathrm{pH}$ of the treated water will be basic at column startup as the resorcinol resin partially hydrolyzes.

Notable differences were observed between the zeolite and the R-F resin, even in the small-column tests. The density of the organic resin was $10 \%$ less than that of process waters; slight changes in operating pressure easily disturbed the resin bed in the small-column experiment. The particle size of the resin varied with $\mathrm{pH}$ - a characteristic that must be accommodated if the resin is to be stripped with acid for subsequent reuse. With extended contact times, both strontium and cesium desorbed from the resin in batch testing. Both cations produced elution peaks much greater than the feed concentration in the column test. The loss in decontamination and the exaggerated solute fronts are probably an indication of a continuous breakdown of the resin structure (and/or, in the case of cesium, displacement by potassium in the feed stream).

\subsection{SORPTION ON SODIUM NONATITANATE}

The applicability of nonatitanate to wastewater treatment still needs to be more fully defined. Nonatitanate absorbs $\mathrm{Mg}$ and $\mathrm{Ca}$, in addition to $\mathrm{Sr}$. The strontium loading is, therefore, dependent on alkaline earth metal content in wastewater. The prediction of strontium sorption is further complicated by sorption kinetics that are dependent on wastewater composition. The rate of strontium sorption, however, becomes less variable as the total metal content of the wastewater increases. Therefore, scaling up the process by incorporating both chemical kinetic parameters, which fluctuate with feed stream composition, and column kinetic parameters will be a sizable task. Employing a water-softening process prior to using nonatitanate might simplify column operation by creating a more consistent feed stream composition.

Nonatitanate also partially hydrolyzes in solution; the loading characteristics of the hydrolyzed form differ from the sodium form. This effect may also have to be incorporated into scaleup calculations. Finally, the integrity of the pellet form of the sorbent needs to be reviewed. Approximately $40 \%$ of the pellets disintegrated to a fine powder in batch studies where long-term mixing ( 1 week) was used. On a positive 
note, the generation of an inorganic secondary waste wouldl reduce the effort required to make a stabilized waste form from the spent nonatitanate sorbent.

\section{CONCLUSIONS}

R-F resin and sodium nonatitanate have been used successfully to treat certain high-level radioactive wastes in which the high sodium content and high alkalinity limit the solubility of alkaline earth metals. However, in dilute systems, such as groundwater and select process wastewaters, the relatively high concentrations of alkaline earth metals limit the sorptive capacity of the same sorbent for radiostrontium and cesium. Although these new sorbents are highly selective for strontium and cesium over sodium ion, there is little selectivity over alkaline earth metals. Thus, the sorbent capacity in process wastewater and groundwater applications is quickly saturated by the relatively high concentrations of magnesium and calcium in these near-neutral waste streams. A water-softening process may be needed upstream of the sorbent column to extend the lifetimes of these materials. However, the economic viability of this scenario will have to be assessed in reference to the baseline zeolite process.

Both the chemical content and the nonselectivity of R-F resin and nonatitanate have a significant impact on the collection of sorption data in dilute aqueous systems. The interpretation of sorption data is compromised because both sorbents contribute significant amounts of excess counterion to a sample and significant amounts of components are removed while treating wastewater simulants. To obtain an accurate measurement of sorbent performance for column applications, the final equilibrium concentrations of simulant components must be equivalent to that of the feed stream. This requirement has necessitated the use of much more concentrated starting solutions in order to estimate sorption ratios for these nonselective sorbents.

If the use of the resin and nonatitanate is be pursued in future wastewater applications, a number of physical parameters will need to be measured. Very few data are available concerning the pore size and structure of these materials, as demonstrated in the number of voids present in Table 2 of this report. Additionally, a small-column test should be performed using nonatitanate pellets so that column parameters can be compared with those obtained for zeolite and R-F resin. The primary radionuclide contaminants in local groundwater are ${ }^{90} \mathrm{Sr}$ and ${ }^{3} \mathrm{H}$. Considering that the estimated strontium sorption ratios for the $\mathrm{R}-\mathrm{F}$ resin and nonatitanate powder are an order of magnitude lower than the ratio for the baseline zeolite, it seems more prudent at this time to perform scoping studies on an alternative sorbent and postpone further data acquisition for the resin and nonatitanate. 
The primary focus in FY 1997 will be to define the sorption characteristics of the molecular sieve, Ionsiv IE-911, specific to process water/groundwater treatment at the Oak Ridge Reservation. A batch kinetic uptake model for ion exchange will be used to predict strontium and cesium sorption on crystalline silicotitanate (CST). This model, which uses the Wilson equation to calculate solid-phase activity coefficients, has been successfully applied to the prediction of cation sorption on chabazite zeolite pellets from process wastewater. Therefore, a direct comparison of CST and baseline zeolite performance can be made. Parameters required to predict cation sorption on the CST will include binary and tertiary cation sorption data and the determination of the time dependence of cation sorption. Due to the amount of laboratory work involved, binary ( $\mathrm{Sr}-\mathrm{Na}, \mathrm{Cs}-\mathrm{Na}, \mathrm{Ca}-\mathrm{Na}$, and $\mathrm{Mg}-\mathrm{Na}$ ) data and time-dependence data will be acquired in FY 1997. These data can then be used to determine the sorption ratios and selectivity of significant cations on the CST. The tertiary data (Sr-Na-Cs, Sr-Na-Ca, Sr-Na-Mg, Cs-Na-Mg, Cs-Na-Ca, $\mathrm{Ca}-\mathrm{Mg}-\mathrm{Na}$ ) will be obtained in FY 1998 in a series of batch tests that will define the interaction of cationic sorption on CST. Data analysis will be used to determine the magnitude of various transport phenomena and to define the diffusion mechanism controlling the sorption process in groundwater applications. Batch data will be used to predict the sorption capacity and the $K_{d}$ of the sorbent for groundwater treatment. Additional parameters will be incorporated after user needs have been defined. A small-column test will be planned, provided that time and funding are available and that the performance of the Ionsiv IE-911 is suitable for groundwater applications. Results of this activity will be summarized and submitted for a journal publication or presented as a milestone draft report, as required. 


\section{REFERENCES}

1. D. T. Bostick, W. D. Arnold, Jr., P. A. Taylor, D. R. McTaggart, M. W. Burgess, and B. Guo, Evaluation of Improved Techniques for the Removal of ${ }^{90} \mathrm{Sr}$ and ${ }^{137} \mathrm{Cs}$ from Process Wastewater and Groundwater: Chabazite Zeolite Baseline Study, ORNL/TM-12903, Oak Ridge National Laboratory, Oak Ridge, Tenn., April 1995.

2. D. T. Bostick, W. D. Arnold, Jr., B. Guo, M. W. Burgess, D. R. McTaggart, and P. A. Taylor, Evaluation of Improved Techniques for the Removal of ${ }^{90} \mathrm{Sr}$ and ${ }^{137} \mathrm{Cs}$ from Process Wastewater and Groundwater: FY 1995 Status, ORNL/TM-13099, Oak Ridge National Laboratory, Oak Ridge, Tenn., March 1996.

3. C. P. Staub, ed., Practical Handbook of Environmental Control, CRC Press, Boca Raton, Fla., 1989.

4. K. Larsen, Boulder Scientific Co., Mead, Colo., personal communication, June 28, 1996.

5. I. DeFilippi, formerly of AlliedSignal Co., personal communication, Dec. 7, 1995.

6. A. Clearfield and J. Lehto, "Preparation, Structure, and Ion-Exchange Properties of $\mathrm{Na}_{4} \mathrm{Ti}_{9} \mathrm{O}_{20} \cdot x \mathrm{H}_{2} \mathrm{O}$,"J. Solid State Chem. 73, 98-106 (1988).

7. S. Yates, I. DeFilippi, M. Andren, R. Gaita, G. Seninara, J. K. Shen, and A. Clearfield, "Novel Ion Exchangers for Strontium and Cesium," presented at DOE Efficient Separations/Processes Technical Information Exchange Meeting, Gaithersburg, Md., Jan. 17, 1996.

8. F. Helfferich, Ion Exchange, Dover Publications, Inc., Mineola, N.Y., 1995, pp. 486-88.

9. Testing Sieves and Their Uses, Handbook 53, 1962 ed., The W. S. Tyler Company, Cleveland, Ohio.

10. J. R. Kaczvinsky, Jr., J. S. Fritz, D. D. Walker, and M. A. Ebra, "The Effects of Reaction Conditions on Porous Chelating Polymers Designed for the Decontamination of Nuclear Waste," J. Radioanal. Nucl. Chem., Articles, 116 (1), 63-75 (1987).

11. R. E. Meyer, W. D. Amold, F. I. Case, G. D. O'Kelley, and J. F. Land, Effects of Mineralogy on the Sorption of Strontium and Cesium onto Calico Hills Tuff, ORNL-6589, Oak Ridge National Laboratory, Oak Ridge, Tenn., April 1990.

12. G. E. Boyd, A. W. Adamson, and L. S. Myers, J. Am. Chem. Soc. 69, 2836 (1947).

13. D. Reichenberg, "Properties of Ion-Exchange Resins in Relation to Their Structure. III. Kinetics of Exchange," J. Am. Chem. Soc. 75, 589-97 (1953).

14. J. Inczédy, Analytical Applications of Ion Exchangers, Pergamon Press, London, 1966, p. 68. 
15. I. M. El-Naggar and M. A. El-Absy, "A Radiochemical Study of the Kinetics of Ion Exchange on Hydrous titanium Dioxide," J. Radioanal. Nucl. Chem., Articles, 157 (2), 313-20 (1992).

16. S. M. Robinson, "Multicomponent Liquid Ion Exchange with Chabazite Zeolites," Ph.D. dissertation, University of Tennessee, Knoxville, 1992.

17. I. DeFilippi, S. Yates, R. Sedath, M. Straszewski, M. Andren, and R. Gaita, Scale-up and Testing of a Novel Ion Exchanger for Strontium (in press).

18. P. K. Sinha, P. K. Panicker, and R. V. Amalraj, "Treatment of Radioactive Liquid Waste Containing Cesium by Indigenously Available Synthetic Zeolites: A Comparative Study," Waste Manage. 15(2), 149-57,(1995).

19. S. M. Robinson, W. D. Arnold, and C. H. Byers, "Mass-Transfer Mechanisms for Zeolite Ion Exchange in Wastewater Treatment," AIChE J. 40 (12), 2045-54, (1994).

20. F. Helfferich, Ion Exchange, Dover Publications, Inc., New York, 1995, p. 264.

21. W. J. Weber, Jr., Physiochemical Processes for Water Quality Control, John Wiley \& Sons, New York, 1972, Chap. 5.

22. Treating ORNL Wastewaters, ORNL/TM-12272, Oak Ridge National Laboratory, Oak Ridge, Tenn., June 1993.

23. S. M. DePaoli and J. J. Perona, "A Model for Sr-Cs-Ca-Mg-Na Ion Exchange Uptake Kinetics on Chabazite," $A I C h E J$. (in press).

24. E. D. Collins, D. O. Campbell, L. J. King, J. B. Knauer, and R. M. Wallace, Evaluation of Zeolite Mixtures for Decontaminating High-Activity-Level Water at the Three Mile Island Unit 2 Nuclear Power Station, IAEA-EC-5 18/4, June 1984.

25. M. S. Doulah and S. A. Jafar, Ion Exchange for Industry, ed. M. Streat, Ellis Horwood Ltd., Chichester, England, 1988, pp. 293-305.

26. S. M. Robinson, T. E. Kent, W. D. Arnold, and J. R. Parrott, Jr., The Development of a Zeolite System for Upgrade of the Process Waste Treatment Plant, ORNL/TM-12063, Oak Ridge National Laboratory, Oak Ridge, Tenn., October 1993. 